\title{
Comparative Study of the Possible Hepatoprotective Effect of Each of N-acetylcysteine, Coenzyme Q1o and Aloe Vera Gel in Acute Acetaminophen Induced Hepatotoxicity in Albino Rats. (Histological and Biochemical Study)
}

\author{
Hoda Fouad Abd El Salam, Haidy M. A.Megahed, Saffa A.M.Abd El Aziz ${ }^{1}$, \\ Mona M. Sobhy² and Hala M. Abd El-Mouaty ${ }^{3}$
}

${ }^{1}$ Department of Forensic Medicine and Clinical Toxicology

2 Medical Biochemistry

${ }^{3}$ Histology and Cell Biology

Faculty of Medicine, University of Alexandria, Alexandria, Egypt

\begin{abstract}
Introduction: Although acetaminophen is a widely used analgesic antipyretic, its toxicity is one of the most common causes of acute liver failure worldwide. N-acetyl cysteine (NAC) is the standard antidote for acute acetaminophen toxicity. Both coenzyme Q10 (CoQ10) and Aloe vera have antioxidant and anti-inflammatory effects so they are used in wide varieties of medical applications Objective: The aim of this work was to compare the possible hepatoprotective effects of NAC, CoQ10 and Aloe vera gel in acute acetaminophen induced hepatotoxicity in albino rats.

Materials \&Methods: Sixty male albino rats were divided into 3 groups, group I (control group) was further subdivided into 4 equal subgroups Ia, Ib, Ic and Id ( $\mathrm{n}=5)$ receiving tap water, NAC $(450 \mathrm{mg} / \mathrm{kg})$ as a single oral dose, CoQ1010mg/kg as a single i.p injection, Aloe vera $(500 \mathrm{mg} / \mathrm{kg}$ ) as a single oral dose respectively. GroupII $(\mathrm{n}=10)$ received acetaminophen $(700 \mathrm{mg} / \mathrm{kg})$ as a single oral dose. Group III was further subdivided into 3 subgroups IIIa, IIIb and IIIc $(n=10)$, each received the same dose of acetaminophen as group II followed 1 hour later by NAC, CoQ10 or Aloe vera gel respectively in the same doses as group I. After 24 hours the rats were sacrificed under anesthesia and blood samples were collected for estimation of serum aspartate transaminase (AST) (Aspartate transaminase AST) and alanine transaminase (ALT) (Alanine transaminase ALT) levels. Liver homogenates were used for estimation of malondialdehyde (MDA), superoxide dismutase (SOD) and reduced glutathione (GSH). Liver specimens were harvested from all rats at the end of the experiment for histological examination by the light and electron microscopes.

Results: Acetaminophen induced hepatotoxicity, as it significantly elevated AST, ALT and MDA and depleted liver GSH and SOD. NAC, CO Q10 and Aloe vera gel had hepatoprotective effects as they reversed these effects. Histologically, group Ib, Ic and Id revealed almost the control pattern of liver similar to group Ia. Group II liver sections showed loss of normal hepatocellular architecture with cellular infiltration and dilated congested blood vessels. Most of the hepatocytes appeared swollen with cytoplasmic vacuolation. Dark shrunken nuclei were encountered. Ultrastructurally, dense mitochondria, dilated profiles of rER and numerous lipid droplets were revealed. Many apoptotic bodies were further encountered. Both group IIIa and IIIc revealed almost the control pattern of the liver except for few areas of cellular infiltration and vascular dilatation and congestion in group IIIa. Group IIIb showed considerable improvement with persistent focal areas of hepatic affection.

Conclusion: This study showed that NAC, CoQ10 and Aloe vera have significant hepatoprotective effects in acetaminophen induced hepatotoxicity, best seen with NAC and Aloe vera gel and less with CoQ10.

Recommendations: Further study is recommended to explore the possible hepatoprotective effects of coenzyme Q10 and Aloe vera in chronic acetaminophen as well as other toxins induced hepatotoxicity.
\end{abstract}

Keywords Acetaminophen, hepatotoxicity, N-acetyl cysteine, Coenzyme Q10, Aloe vera. 


\section{Introduction}

A cetaminophen

[N-acetyl-p-aminophenol, paracetamol] (APAP) is one of the most widely used analgesic antipyretics in the world because of its cheapness and efficacy for the treatment of common pains and colds (Uehara et al 2013). Nowadays it is present either as a single product in several forms such as syrups, tablets, capsules, chewable tablets and suppositories or in combination with other drugs in more than 100 preparations. It is one of the most common causes of poisoning due to pharmaceutical agent (Wexler et al 2005). APAP overdose is the primary cause of acute liver failure throughout the world (Antoine et al 2012 and McGill 2012).

N-acetyl cysteine (NAC) constitutes the central portion of glutathione (GSH) molecule. It is converted in the body into metabolites that can stimulate GSH synthesis, promote detoxification and act directly as free radical scavengers. NAC has historically been administered as a mucolytic agent. However, it appears to have beneficial effects in conditions such as HIV infection, heart disease and cancer. NAC is the cornerstone of treatment for APAP overdose. It is useful in the management of fulminant liver failure caused by toxicologic and non-toxicologic causes (Burke et al 2006). However, NAC administration is associated with possible side effects including hypersensitivity, gastrointestinal disturbances, tachycardia, and hypotension (Barile 2004).

Coenzyme Q10 (CoQ10) is a lipid soluble vitamin-like substance naturally found in nearly all cells of the human body. It is present in a wide range of dietary items such as poultry, meat, fish, vegetable oils and nuts (Visnagri et al 2012). CoQ10 is a powerful antioxidant, it scavenges free radicals (Fouad et al 2013). Co Q10 is synthesized in the human body intracellularly by a very complex process needing multiple vitamins and specific trace elements, and a deficiency of one or more of these components can adversely affect the production of adequate amount. Moreover, tissue levels of Co Q10 decrease with age, due to decreased production, increased requirements or insufficient intake of the precursors. Metabolically active cells, as hepatocytes have the highest demands for Co Q10 and greater susceptibility to its deficiency (Tran and Clarke 2007). Co Q10 has many clinical indications as Parkinson's disease, mitochondrial disorders and cardiovascular diseases (Wagner 2007 and Kaufmann et al 2009).

Aloe Vera plant is a member of the lily family which includes onion and garlic. It has been used for centuries for its health and medicinal care properties. Two thousand years ago, the Egyptians called Aloe "the plant of immortality". It is used in traditional Indian medicine for colic, constipation, skin diseases, worm infestation, and infections. In Chinese medicine, it is often recommended in the treatment of fungal diseases. In Western society, Aloe vera is widely used in the cosmetic, pharmaceutical and food industries.
(Benzie and Wachtel-Galor 2011). The Aloe Vera gel got from the leaves is potent and has as many as 75 ingredients that can improve health (Titus 2013). These include many minerals, vitamins, amino acids, enzymes, sugars, sterols, hormones, anthraquinones and others (Agarwal and Dwivedi 2013). Therefore, it has many mechanisms of action such as antiinflammatory, healing promotion, immuno-modulation, antioxidant, antiseptic and many others (Sahu et al 2013).

In such a context, the present study aimed to investigate and compare the possible hepatoprotective effect of N-acetyl cysteine, coenzyme Q10 and Aloe vera gel in acute acetaminophen induced hepatic toxicity in albino rats.

\section{Materials and methods}

The study was carried out on 60 adult male albino rats weighing 120-150 g. They were housed under the same environmental conditions and allowed free access to water and standard rat chow ad libitum. After one week acclimatization period, they were randomly assigned into three groups.

\section{Chemicals}

- Acetaminophen and NAC were purchased from Sigma-Aldrich in the form of white powder that were dissolved in distilled water and given orally by gavage.

- N acetyl cysteine was purchased from SigmaAldrich in the form of white powder that were dissolved in distilled water and given orally by gavage.

- Co enzyme Q 10 was purchased from SigmaAldrich in the form of yellow powder that was dissolved in Tween 80 which was purchased also from Sigma-Aldrich, and given by intraperitoneal injection.

- Aloe Vera gel was prepared from Aloe vera leaves which were rinsed in ordinary water and the juice was obtained by gently pressing the leaves, dissolved in distilled water and given orally by gavage.

\section{Animal groups \\ Group I (Control group)}

20 rats, were subdivided into four equal subgroups of 5 rats each. Subgroup Ia received tap water, subgroup Ib received $\mathrm{N}$-acetyl cysteine (NAC) as a single oral dose of $450 \mathrm{mg} / \mathrm{kg}$ (Nayak et al 2011), subgroup Ic received Co enzyme Q10 as a single intra-peritoneal injection of $10 \mathrm{mg} / \mathrm{kg}$ (Fouad and Jresat 2012) and subgroup Id received Aloe vera gel as a single oral dose of $500 \mathrm{mg} / \mathrm{kg}$ (Nayak et al 2011).

\section{Group II (Acetaminophen group)}

Included 10 rats that received acetaminophen as a single oral dose of $700 \mathrm{mg} / \mathrm{kg}$ (Fouad and Jresat 2012). 


\section{Group III}

Included 30 rats received acetaminophen the same as group II and 1 hour later they were subdivided into 3 equal sub-groups 10 rats each.

Subgroup IIIa (Acetaminophen + NAC) received NAC as a single oral dose of $450 \mathrm{mg} / \mathrm{kg}$ (Nayak et al 2011).

- Subgroup IIIb (Acetaminophen + CoQ10) received Co Q10 as a single intra-peritoneal injection of 10mg/kg (Fouad and Jresat 2012).

- Subgroup IIIc (Acetaminophen + Aloe vera) received Aloe vera as a single oral dose of $500 \mathrm{mg} / \mathrm{kg}$ (Nayak et al 2011).

Guide lines for the ethical care and treatment of animals from the Local Ethical Committee of the Faculty of Medicine, University of Alexandria were strictly followed.

After 24 hours, all animals were sacrificed under ether anesthesia.

1- Blood samples were collected by cardiac puncture and the sera were separated to be stored at a temperature of $-20^{\circ} \mathrm{C}$ for biochemical analyses.

2- Livers were extracted and divided into 2 portions: one portion was homogenized and the supernatant was used for different biochemical assays. The other portion was used for histological examination.

\section{Liver homogenate preparation:}

Liver was removed and quickly dissected. A portion of it was placed on ice, and immediately homogenized in cold $10 \mathrm{mM}$ Tris- $\mathrm{HCl} \mathrm{pH}$ 7.4. The homogenates were centrifuged at 2,000 xg for 10 minutes to yield the lowspeed supernatant fractions that were used for different biochemical assays. Aliquots of liver preparations were frozen at $-20^{\circ} \mathrm{C}$.

\section{Biochemical analysis}

Serum concentrations of Aspartate transaminase (AST) and Alanine transaminase (ALT) were measured by a colorimetric method (CAT. NO. AT 1034 (45) by using GOT and GPT kits (Reitman and Frankel 1957).

The supernatant of the liver homogenate was used to measure:

1. Reduced glutathione (GSH) by colorimetric method (CAT. NO. GR 2511 ) by using reduced glutathione kit (Moron et al 1979).

2. Lipid peroxide Malondialdehyde (MDA) by colorimetric method (CAT. NO. MD 25 29) by using malondialdehyde kit (Subramanian et al 1988).

3. Superoxide dismutase (SOD) by colorimetric method (CAT. NO. SD 25 21) by using Superoxide dismutase kit (Oyanagui 1984).

All biochemical kits were purchased as colorimetric assay kits from Biodiagnostic Company for diagnostic and research reagents (Cairo, Egypt).

\section{Histological examination}

The liver of each rat was dissected out. A portion of it was divided into two halves. Half of samples were cut into small pieces, immediately fixed in phosphate buffered gluteraldehyde and processed for transmission electron microscopic study at Electron Microscopy Unit, Faculty of Science, Alexandria University (Bancroft and Gamble, 2008).

The other half of samples were fixed in $10 \%$ formol saline. Each specimen was then processed to get $6 \mu \mathrm{m}$ thick paraffin sections to be stained with Hematoxylin and eosin (H\&E) stain (Carleton et al., 1980).

\section{Statistical analysis:}

The Data was collected and entered into the personal computer. Statistical analysis was done using Statistical Package for Social Sciences (SPSS/version 20) software.

Data were expressed as mean \pm standard deviation (SD). They were fed to the computer using Statistical Package of Social Science (IBM SPSS) software package version 20. Statistical analysis was carried out using one way analysis of variance (ANOVA) and Post Hoc test (Scheffe) for pair wise comparison. $\mathrm{P}$ value less than 0.05 was considered statistically significant.

\section{Results}

\section{Biochemical results}

There was no statistically significant difference between control subgroups (Ia, Ib, Ic \& Id) with respect to the studied parameters.

\section{AST levels (U/ml)}

As shown in table (1), the toxicity group (II) showed a significant increase as compared with control group (I) $(\mathrm{P}=0.001)$. On the other hand, there was significant decrease in the AST levels in subgroup IIIa $(p=0.008)$, subgroup IIIb $(\mathrm{p}=0.0001)$ and subgroup IIIc $(\mathrm{p}=0.0073)$ when compared with group II. It is noteworthy that subgroup IIIb measured the least mean AST value among the different subgroups of group III.

\section{ALT levels (U/ml)}

As shown in table (2), there was statistically significant increase in its serum level in the toxicity group (II) as compared to control group (I) $(\mathrm{P}=0.001)$, whereas significant decrease in the ALT levels was revealed in subgroup IIIa $(p=0.021)$, subgroup IIIb $(p=0.01)$ and subgroup IIIc $(\mathrm{p}=0.0023)$ when compared with group II. Moreover, subgroup IIIc showed significantly lower ALT levels as compared to subgroup IIIa and IIIb $(\mathrm{p}=0.021)$

\section{GSH levels in the liver ( $\mathrm{mmol} / \mathrm{g}$ tissue)}

As shown in table (3), there was statistically significant decrease in GSH levels of toxicity group II as compared with control group I $(\mathrm{P}=0.001)$. On the other hand, statistically significant increase in the GSH levels was revealed in subgroup IIIa, subgroup IIIb and subgroup IIIc when compared with group II $(p=0.0001)$. Comparing different subgroups of group III, subgroup IIIc measured significantly higher GSH values with respect to the other subgroups $(\mathrm{p}=0.002)$. MDA levels in the liver (nmol/g tissue) 
As shown in table (4), there was statistically significant increase in the MDA levels in acetaminophen group II as compared to control group I $(\mathrm{P}=0.001)$. In contrast, there was a significant decrease in the MDA levels in subgroup IIIa, subgroup IIIb and subgroup IIIc when compared with group II $(\mathrm{p}=0.001)$. No significant difference was encountered between different subgroups of group III.

\section{SOD levels in the liver ( $\mathrm{U} / \mathrm{g}$ tissue)}

As shown in table (5), there was a significant decrease in the SOD levels in acetaminophen group II when compared with the control group I $(\mathrm{P}=0.001)$. On the contrary, statistically significant increase in the SOD levels was revealed in subgroup IIIa, subgroup IIIb and subgroup IIIc when compared with group II $(\mathrm{p}=0.001)$. Comparing subgroups of group III, subgroup IIIa measured significantly higher values $(\mathrm{p}=0.004)$.

\section{Histological results}

\section{Group I (control group) Hematoxylin and Eosin (H\&E) stain}

The light microscopic examination of liver sections of the control group (subgroups Ia, Ib, Ic and Id) revealed almost the same histological pattern of the liver. The sections showed normal hepatic architecture; the hepatic lobules appeared to be made up of hepatocytes arranged in cords radiating from the central veins. The portal tracts were seen at the periphery of hepatic lobules (Fig. 6a). The hepatocytes were polyhedral in shape with granular acidophilic cytoplasm and rounded vesicular centrally located nuclei, some cells were binucleated. In between the hepatic cords, blood sinusoids appeared as narrow spaces lined by flattened endothelial cells and few bulging Kupffer cells (Fig. $6 b)$. The portal tracts showed one bile duct radicle, a branch of the hepatic artery and a branch of the portal vein, all were enclosed by scanty amount of connective tissue (Fig. 6a).

\section{Group II (Acetaminophen group)}

The liver sections of group II rats showed severe hepatic affection in the form of centrilobular necrosis. The hepatic architecture was disorganized with marked affection of most of the hepatocytes. The majority of blood sinusoids between the affected hepatic cords showed narrowing or even complete obliteration (Fig. 7 a-c \& 8a). The hepatocytes appeared swollen with excessive vacuolation of their cytoplasm especially at centrilobular areas (Fig. 7a-c \& 8a). However, some lobules showed extensive vacuolation of hepatocytes all over the classical lobules even those at the periphery surrounding the portal tracts (Fig. 8b). Some cells appeared with eccentric dark nuclei, others appeared with karyolytic nuclei. Few cells were shrunken with acidophilic cytoplasm and small deeply stained eccentric nuclei. Scattered necrotic foci were also seen with destruction of cell boundaries and disappearance of the nuclei (Fig. $8 \mathrm{a} \& \mathrm{~b}$ ). Some of the central veins and portal blood vessels appeared dilated and congested (Fig. 7a \&c). The portal area revealed evident proliferation of bile ducts (Fig. 8b).
Mononuclear cellular infiltration was observed (Fig. 7b \&c).

\section{Group III}

- Subgroup IIIa: (Acetaminophen + NAC):

Examination of liver sections of subgroup IIIa rats revealed preserved architecture of the hepatic lobules. The hepatocytes, even those near the central vein, were arranged in cords separated by blood sinusoids (Fig. 9a $\& b)$. They were polyhedral in shape with acidophilic cytoplasm. Many cells were binucleated (Fig. 9b). Nevertheless, dilated central veins were evident (Fig. 9c). Mononuclear cellular infiltration was further observed (Fig. 9a \&b).

- Subgroup IIIb: (Acetaminophen+ CoQ10):

The histological sections of liver of subgroup IIIb rats revealed moderately or less preserved architecture of hepatic lobules with dilatation of the intervening sinusoids and proliferation of bile ducts (Fig. 10a). Many hepatocytes appeared polyhedral in shape with acidophilic cytoplasm and central vesicular nuclei. Others showed vacuolated cytoplasm and deeply stained nuclei (Fig. 10b \&c). Cellular infiltration in the portal tract was further revealed (Fig. 10a).

- Subgroup IIIc: (Acetaminophen + Aloe vera):

The liver sections of rats of subgroup IIIc revealed preserved architecture of hepatic lobules (Fig. 11a). The hepatocytes were arranged in cords radiating from the central vein and separated by blood sinusoids (Fig. 11a \&b). The cells were polyhedral in shape with acidophilic cytoplasm and central vesicular nuclei. Many cells were binucleated (Fig. 11b \&c). The portal tract appeared nearly similar to the control group (Fig. $11 \mathrm{a} \& \mathrm{c})$.

\section{Electron microscopic results Group I (control group)}

Electron microscopic examination of hepatocytes of both negative and positive control subgroups showed almost the same normal hepatic ultrastructure. The hepatocytes were polygonal in shape with rounded euchromatic smooth contoured nuclei containing prominent nucleoli. Their cytoplasm showed numerous mitochondria with lamellar cristae, arrays of rough endoplasmic reticulum and smooth endoplasmic reticulum. Glycogen particles appeared as electron dense aggregates (Fig. 12 a \& b). Bile canaliculi were seen as narrow spaces limited by short microvilli of adjacent hepatocytes and firmly bounded by desmosomes (Fig. 12 b). The perisinusoidal space of Disse was seen with many microvilli of hepatocytes protruding into it. Kupffer cells were seen lining the blood sinusoids as well (Fig. 13).

\section{Group II (Acetaminophen group)}

Examination of group II rat liver revealed marked ultrastructural alterations. The cytoplasm of most cells showed accumulation of numerous large electron lucent lipid droplets (Fig. 14-16). It also revealed pleomorphic mitochondria with dense matrix, dilated rough endoplasmic reticulum with partial degranulation and dilated smooth endoplasmic reticulum (Fig. 14- 
16). Some giant mitochondria were encountered (Fig. 16). Some cells although depicted normal looking nuclei, however, showed areas of rarified cytoplasm containing small dark mitochondria (Fig. 17). Some liver cells exhibited many lysosomes (Fig. 14\&19). Many hepatocytes' nuclei were irregular, shrunken and electron dense (Fig. 19). Dilated perinuclear cisternae were seen in most of the nuclei (Fig. 15 a \&b). Dilated bile canaliculi, bounded by desmosomes, in between the hepatocytes with exaggerated microvillus borders were observed (Fig. 19). Kupffer cells were prominent with irregular heterochromatic nuclei. Their cytoplasm revealed vacuoles and lysosomes (Fig. 14 \& 15a). Apoptotic bodies containing aggregated cytoplasmic organelles were seen frequently (Fig. $18 \mathrm{a} \& \mathrm{~b}$ ).

\section{Group III (Acute acetaminophen toxicity group with possible hepatoprotective agent): \\ - Subgroup IIIa: (Acetaminophen group + NAC):}

Electron microscopic examination of liver specimens of subgroup IIIa revealed that co-administration of NAC with acetaminophen ameliorated most of the hepatocyte affection. The nuclei of most of the examined cells were euchromatic with regular contour (Fig. 20 a\& b). Few cells showed mildly dilated perinuclear cisterae (Fig. 21). Their cytoplasm revealed mildly dilated profiles of rough endoplasmic reticulum and pleomorphic mitochondria with slightly dense matrix (Fig. 20b \& 21). Binucleated cells were depicted as well (Fig. 21). Bile canaliculi with normal size were also revealed (Fig. 20b \& 21).

\section{- Subgroup IIIb: (Acetaminophen group + CoQ10):}

Electron microscopic examination of liver specimens of subgroup IIIb revealed moderate ultrastructural changes of many hepatocytes. The nuclei of many cells were euchromatic with regular contour. Their cytoplasm revealed almost the control ultrastructural pattern (Fig. 22a). Some cells showed irregular nuclei with dilated perinuclear cisterna (Fig. 23), dilated profiles of rough endoplasmic reticulum and pleomorphic mitochondria with dense matrix (Fig. 22b \& 23). Many bile canaliculi bounded by desmosomes, in between the hepatocytes were further encountered (Fig. 23). Apoptotic bodies with aggregated cytoplasmic organelles in the blood sinusoids were also seen (Fig. 24b). Additionally, blood sinusoids lined by prominent Kupffer cells were observed (Fig. 25). Cellular infiltration was depicted as well (Fig. 24a).

- Subgroup IIIc: (Acetaminophen group + Aloe vera):

Electron microscopic examination of rat liver of subgroup IIIc revealed nearly normal ultrastructural appearance of hepatocytes. Their nuclei were euchromatic with regular contour and prominent nucleoli. Their cytoplasm showed normal profiles of rough and smooth endoplasmic reticulum, numerous mitochondria and glycogen granules (Fig. 26-28). Many binucleated cells were encountered (Fig. 28). Few cells showed electron dense mitochondria (Fig. 27).

Table (1): Comparison between different studied groups regarding serum AST (U/ml).

\begin{tabular}{|c|c|c|c|c|c|c|c|c|}
\hline & \multicolumn{4}{|c|}{ Control group } & \multirow{2}{*}{ Group II } & \multicolumn{3}{|c|}{ Group III } \\
\hline & Ia & Ib & Ic & Id & & IIIa & IIIb & IIIc \\
\hline Mean \pm SD & $\begin{array}{c}52.00 \\
\pm 12.51\end{array}$ & $48.00 \pm 9.67$ & $\begin{array}{l}58.32 \\
\pm 3.23 \\
\end{array}$ & $\begin{array}{l}53.80 \\
\pm 8.20 \\
\end{array}$ & $\begin{array}{l}182.23 \\
\pm 14.11\end{array}$ & $\begin{array}{l}110.22 \\
\pm 12.66\end{array}$ & $\begin{array}{l}77.56 \\
\pm 8.32\end{array}$ & $\begin{array}{l}101.56 \\
\pm 13.59\end{array}$ \\
\hline $\begin{array}{l}\mathrm{F} \\
\mathrm{P} \\
\end{array}$ & \multicolumn{8}{|c|}{$\begin{array}{c}28.55 \\
0.0001 *\end{array}$} \\
\hline $\begin{array}{l}\text { F1 } \\
\text { P } \\
\text { LSD }\end{array}$ & & & & & & \multicolumn{3}{|c|}{$\begin{array}{c}8.65 \\
0.013^{*} \\
\mathrm{~b} \# \mathrm{a}, \mathrm{c}\end{array}$} \\
\hline $\mathrm{P} 1$ & & & 0.001 & & & & & \\
\hline $\mathrm{P} 2$ & & & & & & $0.008 *$ & & \\
\hline P3 & & & & & & & $0.0001 *$ & \\
\hline $\mathrm{P} 4$ & & & & & & & & $0.0073^{*}$ \\
\hline
\end{tabular}

Statistical comparison was done by ANOVA test F: comparison between the three studied groups and their subgroups. F1: comparison between subgroups of group III. LSD = least significant difference (between subgroups of group III).

P1: comparison between group I and group II. P2: comparison between group II and subgroup IIIa.

P3: comparison between group II and subgroup IIIb.P4: comparison between group II and subgroup IIIc.

$P$ : propability of significance (* significant al level $\leq 0.05$ ). 
Table (2): Comparison between different studied groups regarding serum ALT (U/ml).

\begin{tabular}{|c|c|c|c|c|c|c|c|c|}
\hline \multirow[t]{2}{*}{. } & \multicolumn{4}{|c|}{ Control group } & \multirow{2}{*}{ Group II } & \multicolumn{3}{|c|}{ Group III } \\
\hline & Ia & Ib & Ic & Id & & IIIa & IIIb & IIIc \\
\hline Mean \pm SD. & $\begin{array}{c}28.40 \pm \\
13.30\end{array}$ & $\begin{array}{c}50.00 \\
6.08\end{array}$ & $\begin{array}{c}45.36 \pm \\
3.14\end{array}$ & $\begin{array}{c}40.90 \pm \\
11.90\end{array}$ & $\begin{array}{c}60.00 \pm \\
7.45\end{array}$ & $\begin{array}{c}43.11 \pm \\
8.45\end{array}$ & $\begin{array}{c}37.33 \pm \\
5.13\end{array}$ & $\begin{array}{c}33.11 \pm \\
8.12\end{array}$ \\
\hline $\begin{array}{l}\mathrm{F} \\
\mathrm{P}\end{array}$ & \multicolumn{8}{|c|}{$\begin{array}{c}52.5 \\
0.001 * \\
\end{array}$} \\
\hline $\begin{array}{l}\text { F1 } \\
\text { P } \\
\text { LSD }\end{array}$ & & & & & & \multicolumn{3}{|c|}{$\begin{array}{c}5.65 \\
0.021 * \\
\mathrm{c} \# \mathrm{a}, \mathrm{b}\end{array}$} \\
\hline P1 & & & $0.001 *$ & & & & & \\
\hline $\mathrm{P} 2$ & & & & & & $0.021 *$ & & \\
\hline $\mathrm{P} 3$ & & & & & & & $0.01 *$ & \\
\hline $\mathrm{P} 4$ & & & & & & & & $0.0023 *$ \\
\hline
\end{tabular}

Statistical comparison was done by ANOVA test F: comparison between the three studied groups and their subgroups. F1: comparison between subgroups of group III. LSD = least significant difference (between subgroups of group III).

P1: comparison between group I and group II. P2: comparison between group II and subgroup IIIa.

P3: comparison between group II and subgroup IIIb. P4: comparison between group II and subgroup IIIc.

$P$ : propability of significance (* significant al level $\leq 0.05$ ).

Table (3): Comparison between different studied groups regarding GSH level (mmol/g).

\begin{tabular}{|c|c|c|c|c|c|c|c|c|}
\hline & \multicolumn{4}{|c|}{ Control group } & \multirow{2}{*}{ Group II } & \multicolumn{3}{|c|}{ Group III } \\
\hline & Ia & Ib & Ic & Id & & IIIa & IIIb & IIIc \\
\hline $\begin{array}{l}\text { Mean } \pm \\
\text { SD. }\end{array}$ & $\begin{array}{c}21.27 \pm \\
2.52\end{array}$ & $\begin{array}{c}19.99 \pm \\
1.17\end{array}$ & $\begin{array}{c}20.47 \pm \\
1.74\end{array}$ & $\begin{array}{c}20.71 \pm \\
1.68\end{array}$ & $\begin{array}{c}1.55 \pm \\
0.24\end{array}$ & $\begin{array}{c}12.74 \pm \\
2.20\end{array}$ & $\begin{array}{c}10.49 \pm \\
1.50\end{array}$ & $\begin{array}{c}19.76 \pm \\
0.65\end{array}$ \\
\hline $\begin{array}{l}\mathrm{F} \\
\mathrm{P}\end{array}$ & \multicolumn{8}{|c|}{$\begin{array}{c}30.56 \\
0.0001 *\end{array}$} \\
\hline $\begin{array}{l}\text { F1 } \\
\text { P } \\
\text { LSD }\end{array}$ & & & & & & \multicolumn{3}{|c|}{$\begin{array}{c}11.65 \\
0.002 * \\
\mathrm{c} \# \mathrm{a}, \mathrm{b}\end{array}$} \\
\hline $\mathrm{P} 1$ & \multicolumn{5}{|c|}{$0.001 *$} & & & \\
\hline $\mathrm{P} 2$ & & & & & & $0.0001 *$ & & \\
\hline $\mathrm{P} 3$ & & & & & & & $0.0001 *$ & \\
\hline P4 & & & & & & & & $0.0001 *$ \\
\hline
\end{tabular}

Statistical comparison was done by ANOVA test

F; comparison between the three studied groups and their subgroups. F1: comparison between subgroups of group III LSD = least significant difference (between subgroups of group III).P1: comparison between group I and group II.

P2: comparison between group II and subgroup IIIa.P3: comparison between group II and subgroup IIIb.

P4: comparison between group II and subgroup IIIc. P: propability of significance (* significant al level $\leq 0.05$ ).

Table (4): Comparison between different studied groups regarding MDA level (nmol/g).

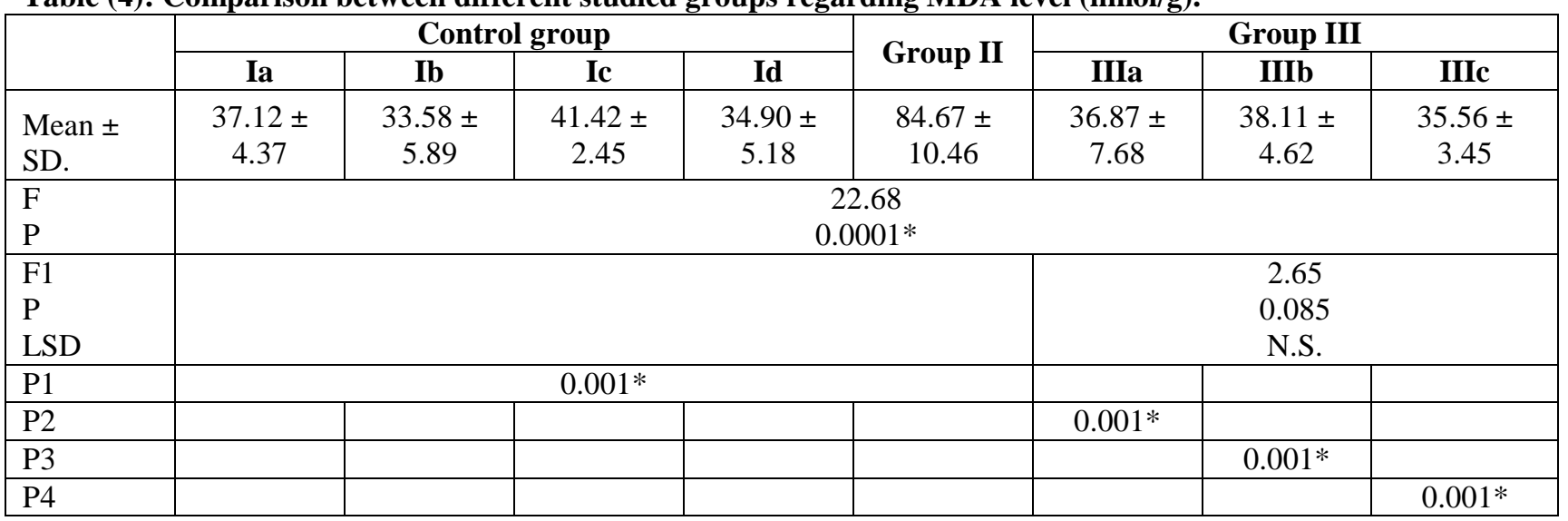

Statistical comparison was done by ANOVA test F comparison between the three studied groups and their subgroups.

F1 comparison between subgroups of group III.LSD = least significant difference (between group III).

P1 comparison between group I and group II.P2 comparison between group II and subgroup IIIa.

P3 comparison between group II and subgroup IIIb.P4 comparison between group II and subgroup IIIc.

$P$ propability of significance (* significant al level $\leq 0.05)$. 
Table (5): Comparison between different studied groups regarding SOD level (U/g).

\begin{tabular}{|c|c|c|c|c|c|c|c|c|}
\hline & \multicolumn{4}{|c|}{ Control group } & \multirow{2}{*}{ Group II } & \multicolumn{3}{|c|}{ Group III } \\
\hline & Ia & Ib & Ic & Id & & IIIa & IIIb & IIIc \\
\hline Mean & 462.60 & 460.40 & 423.60 & 438.02 & 235.00 & 549.00 & 499.00 & 421.11 \\
\hline$\pm \mathrm{SD}$ & \pm 57.56 & \pm 68.82 & \pm 13.60 & \pm 50.97 & \pm 40.47 & \pm 88.62 & \pm 71.48 & \pm 49.66 \\
\hline $\mathrm{F}$ & \multirow{2}{*}{\multicolumn{8}{|c|}{$\begin{array}{c}36.6 \\
0.0001^{*}\end{array}$}} \\
\hline $\mathrm{p}$ & & & & & & & & \\
\hline $\mathrm{F} 1$ & & & & & & \multirow{3}{*}{\multicolumn{3}{|c|}{$\begin{array}{c}8.25 \\
0.004 * \\
\mathrm{a} \# \mathrm{~b}, \mathrm{c}\end{array}$}} \\
\hline $\mathrm{P}$ & & & & & & & & \\
\hline LSD & & & & & & & & \\
\hline P1 & \multicolumn{5}{|c|}{$0.001 *$} & & & \\
\hline $\mathrm{P} 2$ & & & & & & $0.001 *$ & & \\
\hline P3 & & & & & & & $0.001 *$ & \\
\hline $\mathrm{P} 4$ & & & & & & & & $0.001 *$ \\
\hline
\end{tabular}

Statistical comparison was done by ANOVA test F: comparison between the three studied groups and their subgroups. F1: comparison between subgroups of group III.LSD = least significant difference (between subgroups of group III). P1; comparison between group I and group II.P2: comparison between group II and subgroup IIIa.

P3: comparison between group II and subgroup IIIb.P4: comparison between group II and subgroup IIIc.

$P$ : propability of significance (* significant al level $\leq 0.05$ ).

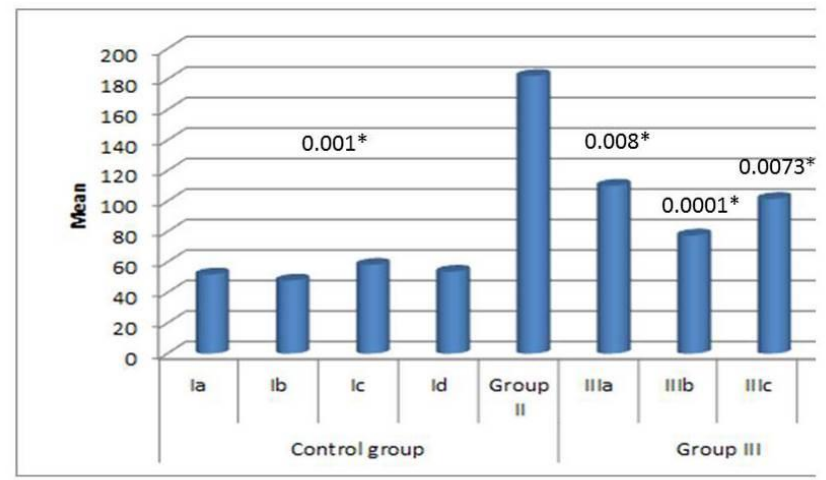

Figure 1: Comparison between different studied groups regarding serum AST (U/ml).

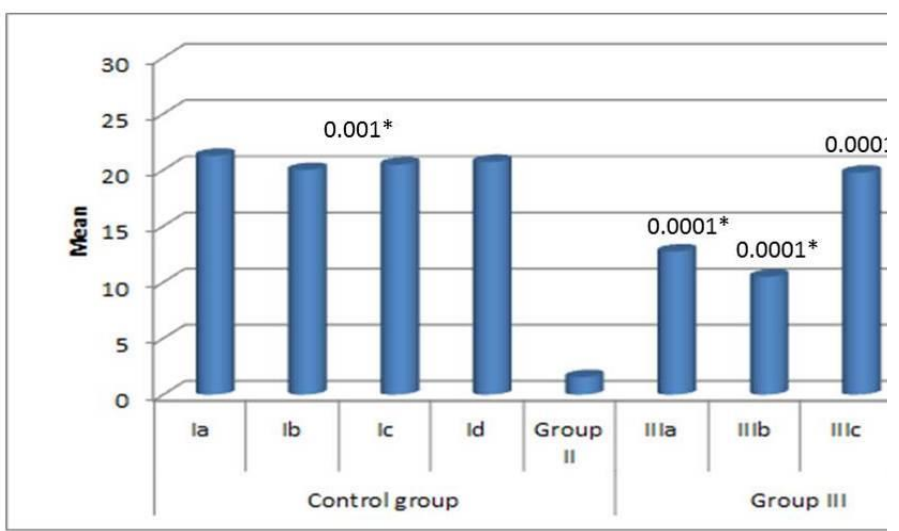

Figure 3: Comparison between different studied groups regarding GSH level ( $\mathrm{mmol} / \mathrm{g})$.

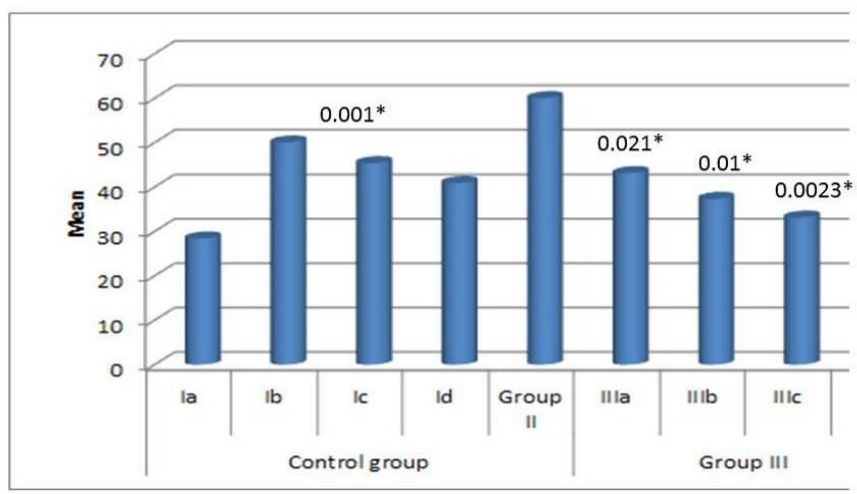

Figure 2: Comparison between different studied groups regarding serum ALT (U/ml).

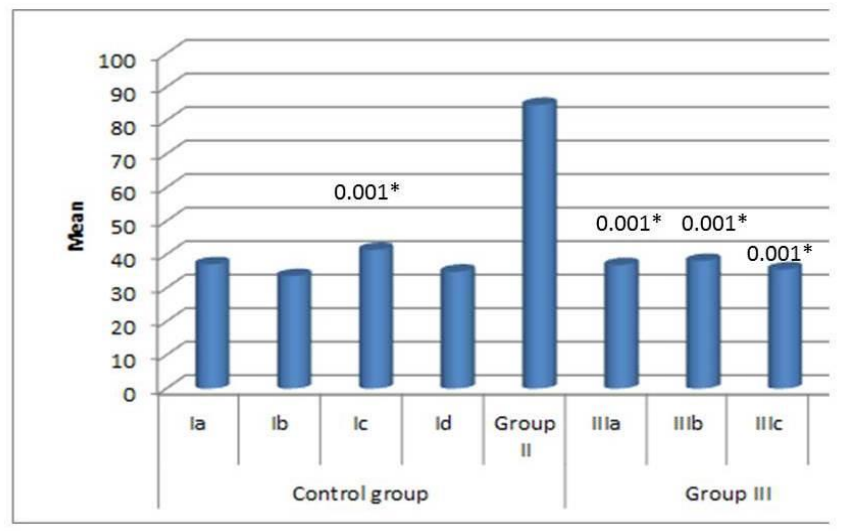

Figure 4: Comparison between different studied groups regarding MDA level (nmol/g). 


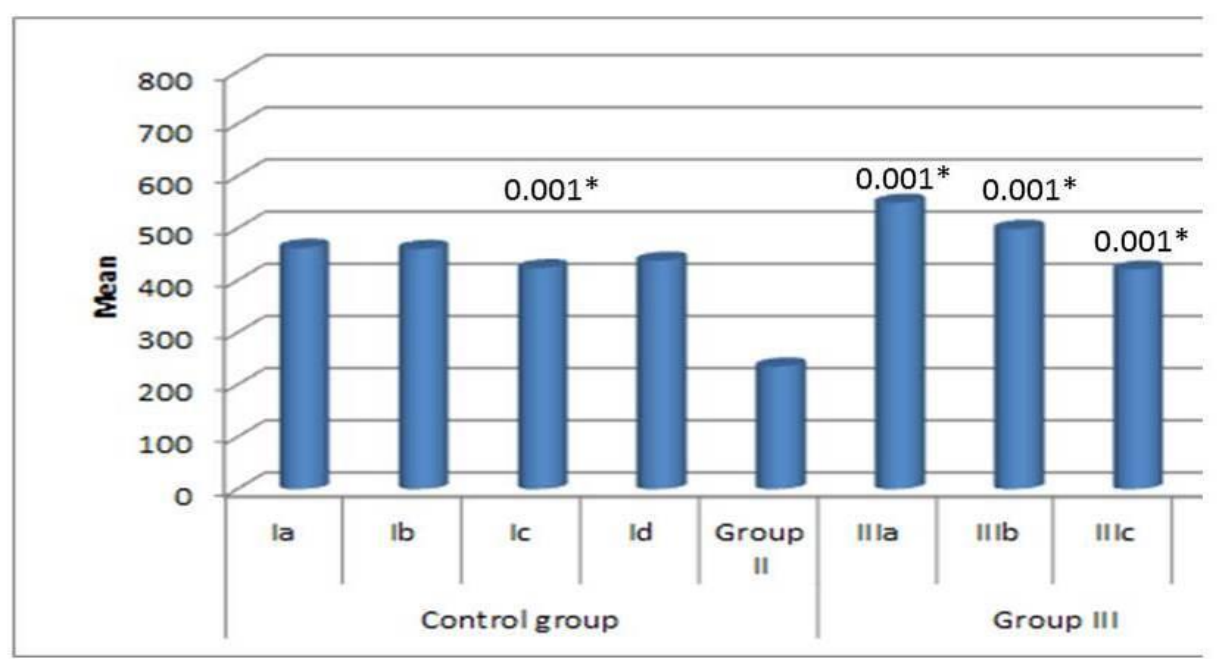

Figure 5: Comparison between different studied groups regarding SOD level (U/g).

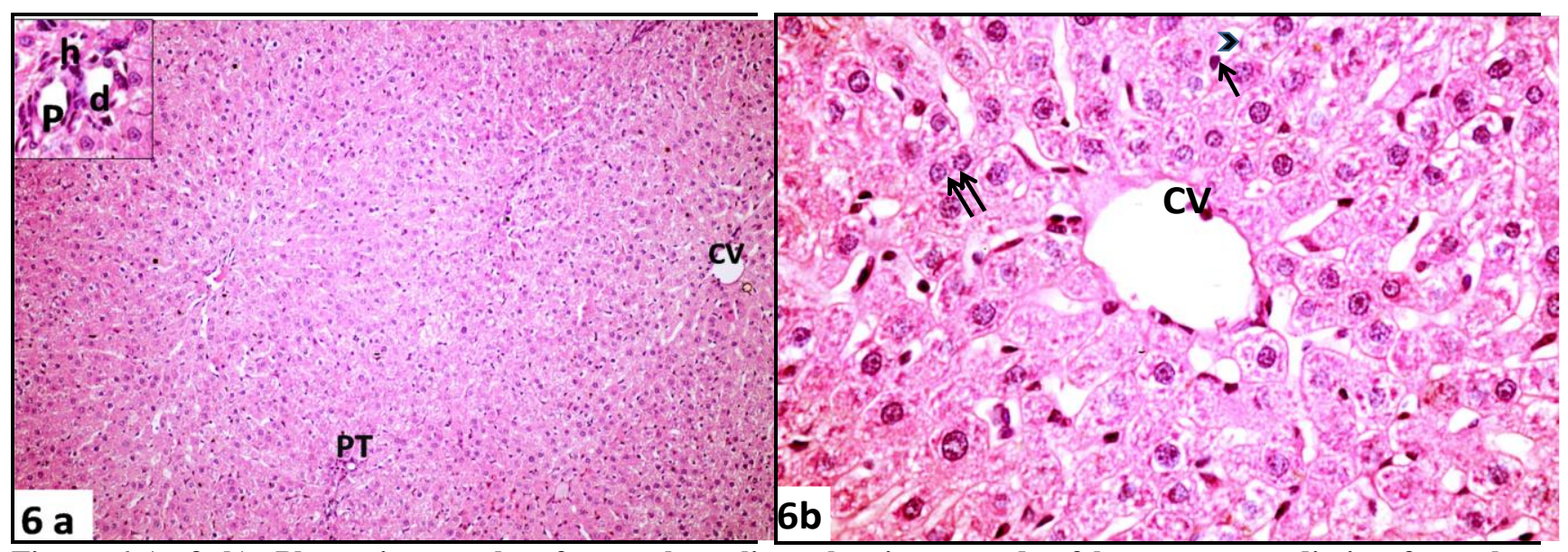

Figure 6 (a \& b): Photomicrographs of control rat liver showing a:cords of hepatocytes radiating from the central vein $(\mathrm{CV})$ and separated by blood sinusoids. Portal tract (PT) is seen at the corner of the classical hepatic lobule. Inset: showing portal tract with its structures; branches of portal vein (p), hepatic artery (h) and bile duct (b). b: A higher magnification revealing polyhedral hepatocytes with slightly vacuolated acidophilic granular cytoplasm and vesicular nuclei. Blood sinusoids separating the hepatic cords are lined by endothelial cells (arrow head) and few Kupffer cells (arrow). Occasional binucleated hepatocytes are also seen (double arrows). (H\&E stain, Mic. Mag. a x100, b \&inset $\times$ 400) 


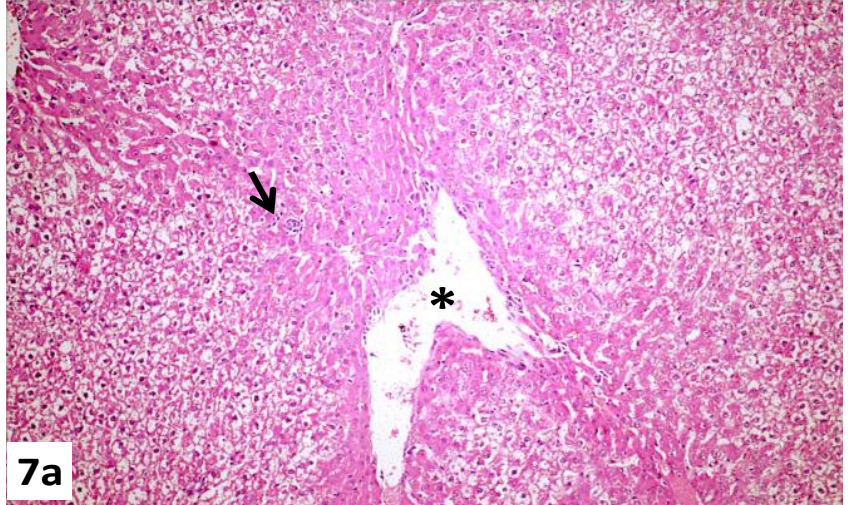

Figure 7 (a, b \& c): Photomicrographs of liver of acetaminophen group II rats (received $700 \mathrm{mg} / \mathrm{kg}$ acetaminophen as a single oral dose) (a \& b): disorganized hepatic architecture and narrowing or even obliteration of large number of blood sinusoids. Many hepatocytes are ballooned with vacuolated cytoplasm and deeply stained nuclei. a: prominent nuclei of Kupffer cells (arrow head) lining the blood sinusoids and dilated portal tract vein (*) are depicted. b: swollen vacuolated hepatocytes with dark nuclei $(*)$, while those at the periphery of the classical lobules surrounding the portal tract (PT) show acidophilic cytoplasm and vesicular nuclei. Note: foci of cellular infiltration (arrow). c: congested central (CV) and portal tract $(\mathrm{PT})$ veins. Note, periportal cellular infiltrations (arrow). (H\&E stain, Mic. Mag. × 100)
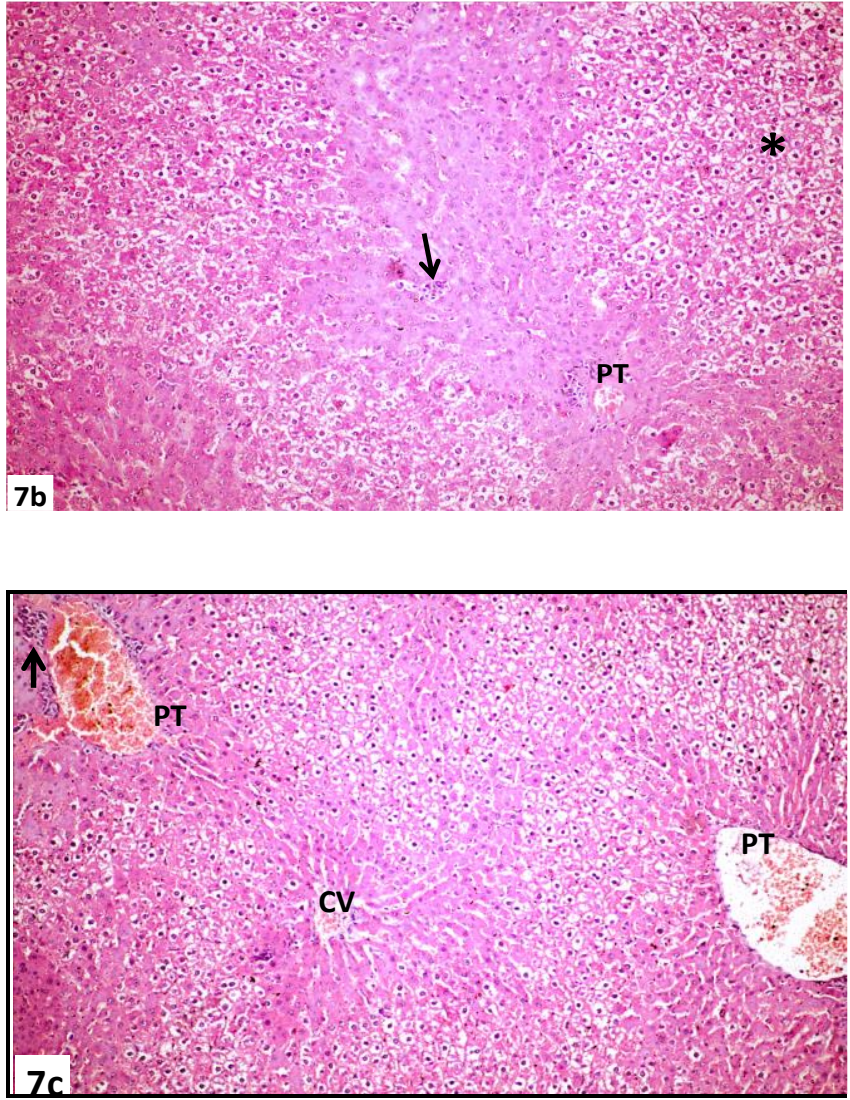
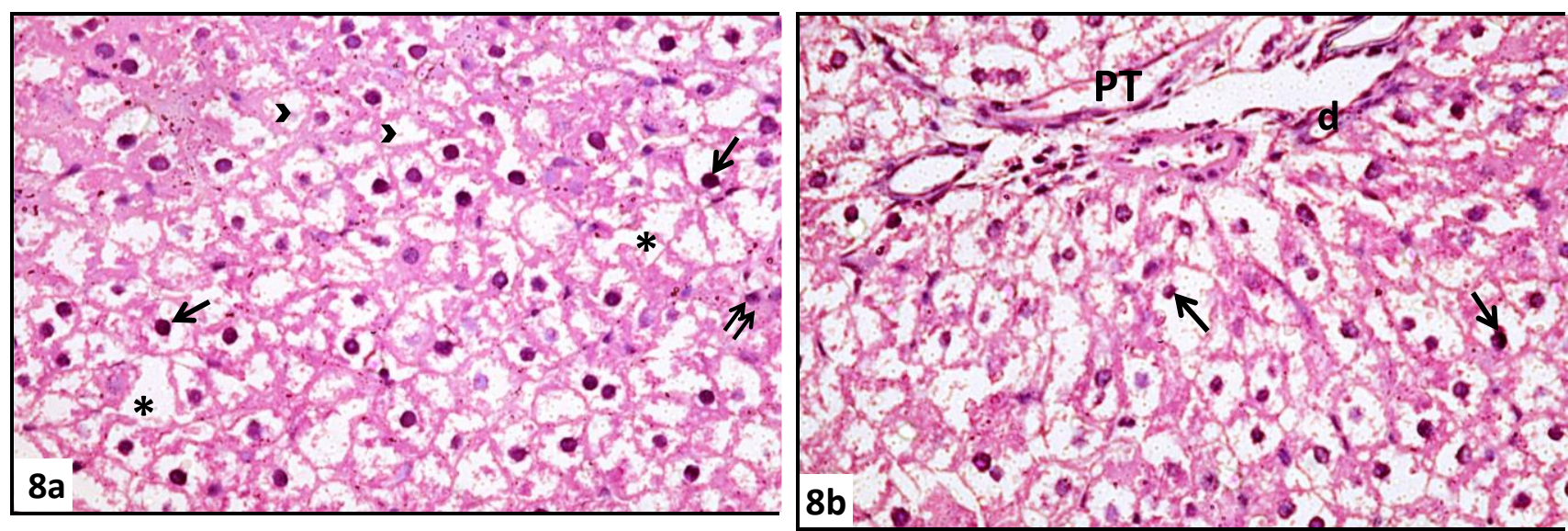

Figure 8 (a \& b): High power view of liver of group II rats, showing ballooning and extensive cytoplasmic vacuolation of the majority of hepatocytes. Some cells show dark eccentric nuclei (arrow), others reveal karyolytic nuclei (arrow head). Few cells appear shrunken with deeply acidophilic cytoplasm and small dense nuclei (double arrows). The portal tract (PT) shows proliferation of bile ducts (d). Note, necrotic areas with destruction of cell boundaries and disappearance of the nuclei (*). (H\&E stain, Mic. Mag. $\times$ 400) 


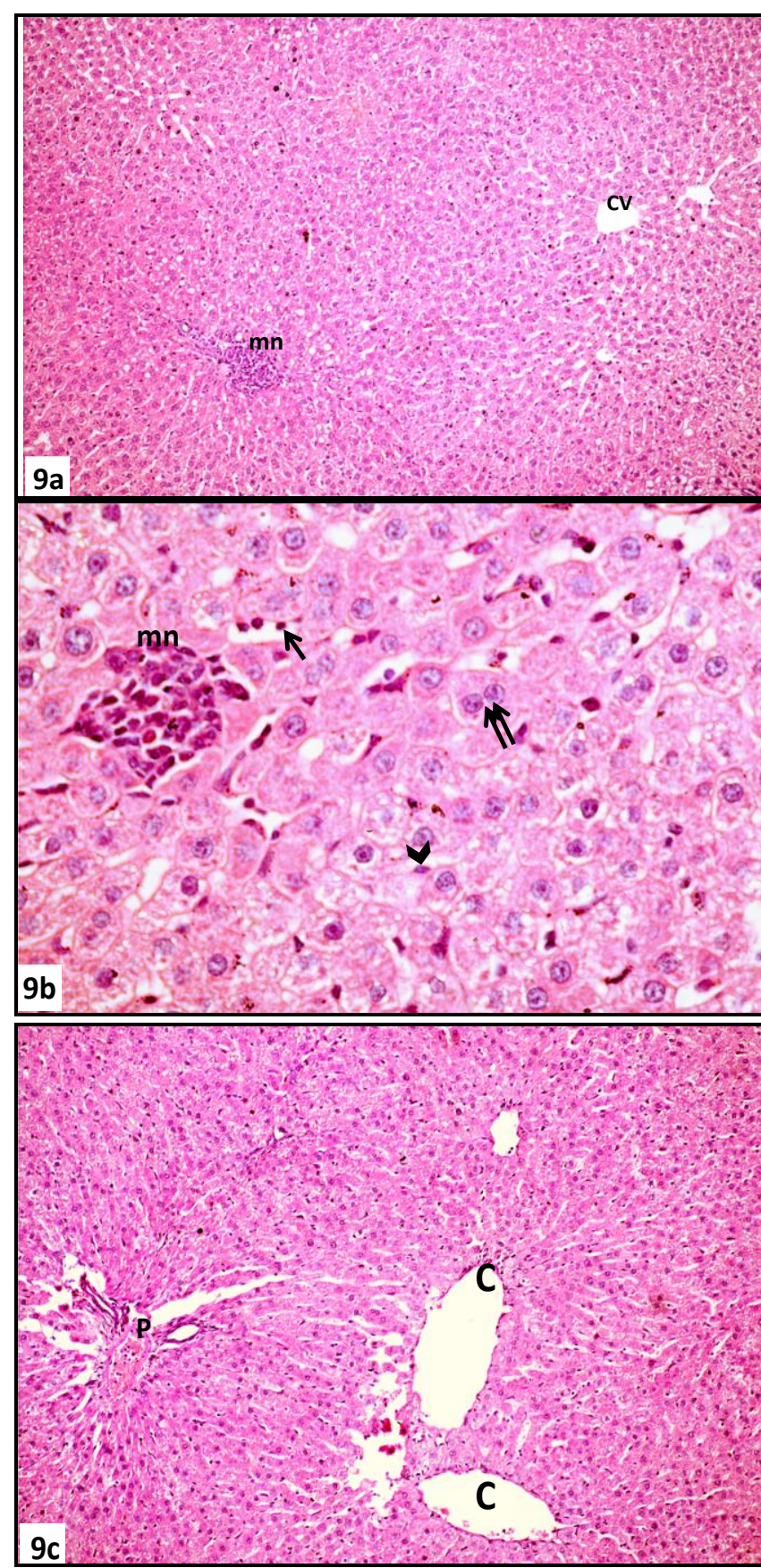

Figure 9 (a, b \& c): Photomicrographs of liver of subgroup IIIa rats (acetaminophen + NAC) showing $\underline{a}_{\text {, }}$ $\underline{\text { b: }}$ preserved architecture of hepatic lobules. Hepatocytes appear arranged in cords radiating from the central vein $(\mathrm{CV})$. They are polyhedral in shape with slightly vacuolated acidophilic granular cytoplasm and vesicular nuclei. Blood sinusoids are lined by endothelial cells (arrow head) and some Kupffer cells (double arrows). Some binucleated hepatocytes are also seen (arrow). Note: cellular infiltration (mn), c: dilated central veins $(\mathrm{C})$ and dilated congested portal vein (P). (H\&E stain, Mic. Mag. a, $c \times 100 \& b \times 400$ )
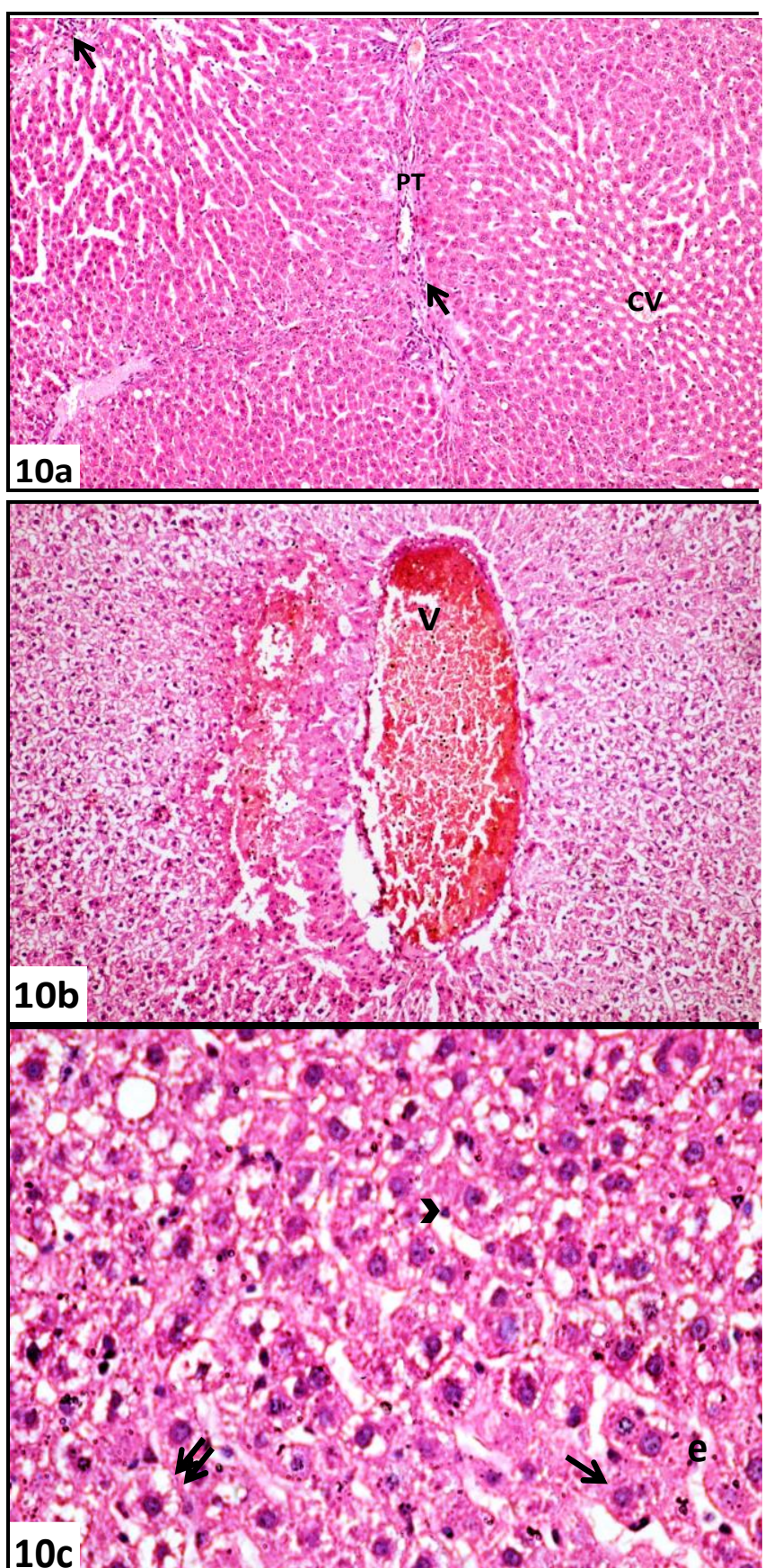

Figure $10(a, b$ \& c): Photomicrographs of rat liver of subgroup IIIb rats (acetaminophen + CoQ10) showing a: moderately preserved architecture of hepatic lobules with dilated blood sinusoids. Proliferation of bile ducts in the portal tract (PT) is also seen. Periportal cellular infiltration (arrow) is also depicted. CV; central vein. b: hepatocytes with swollen vacuolated cytoplasm and deeply stained nuclei around a dilated congested vein (V). c: high power view of some hepatocytes with acidophilic granular cytoplasm and vesicular nuclei (arrow), others exhibit vacuolated cytoplasm (double arrow). e; endothelial cell, arrow head; Kupffer cell. (H\&E stain, Mic. Mag. a, b × $100 \& c \times 400$ ) 


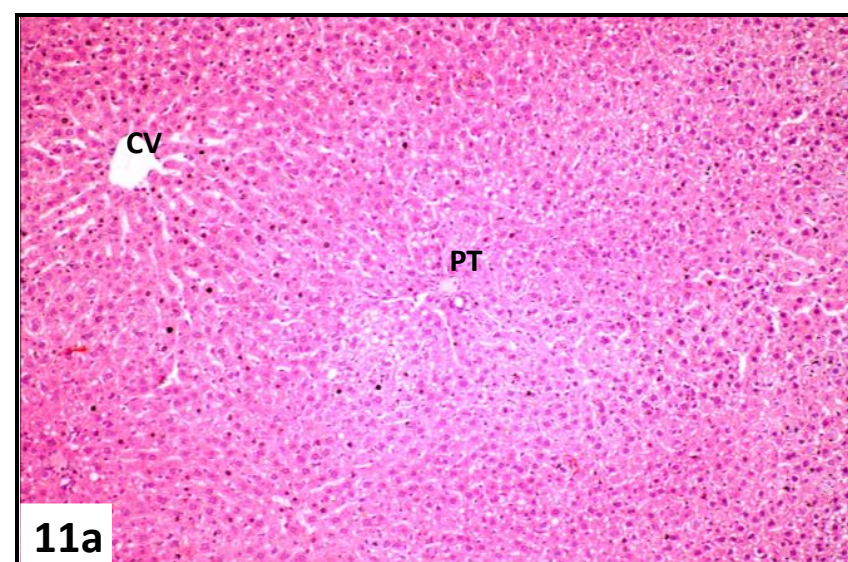

Figure $11(a, b \&$ c): Photomicrographs of liver of subgroup IIIc rats (acetaminophen + Aloe vera) showing classical hepatic lobulation formed of plates of liver cells radiating from central vein (CV) and demarcated by portal tracts at their periphery (PT). $\underline{b}$ \& c: polyhedral liver cells with acidophilic granular cytoplasm and vesicular nuclei (CV) are seen. Many cells are binucleated (double arrow). Blood sinusoids are lined by endothelial cells (arrow head) and Kupffer cells (arrow). The portal tract has nearly normal appearance. $\mathrm{d}$; bile duct.

(H\&E stain, Mic. Mag. a $\times 100$ b \& c × 400)
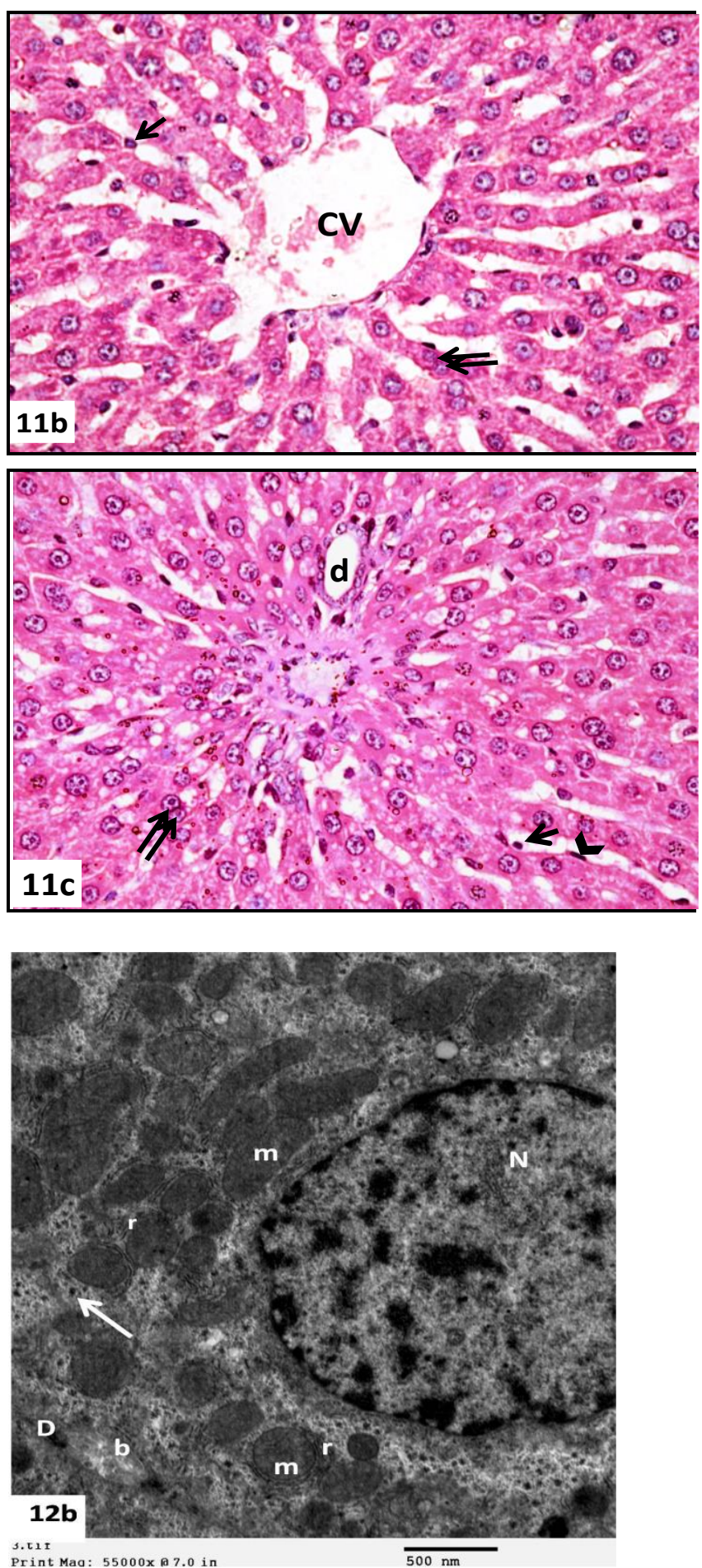

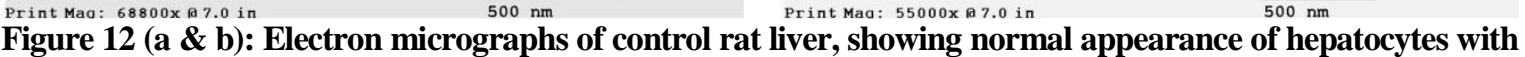
regularly contoured euchromatic nuclei $(\mathrm{N})$. The cytoplasm shows parallel arrays of rough endoplasmic reticulum (r), numerous mitochondria with lamellar cristae $(m)$ and glycogen granules (arrow). Note: a bile canaliculus (b) with microvilli protruding into the lumen enclosed between two adjacent hepatocytes and bounded by desmosomes (D). nu; nucleolus. 


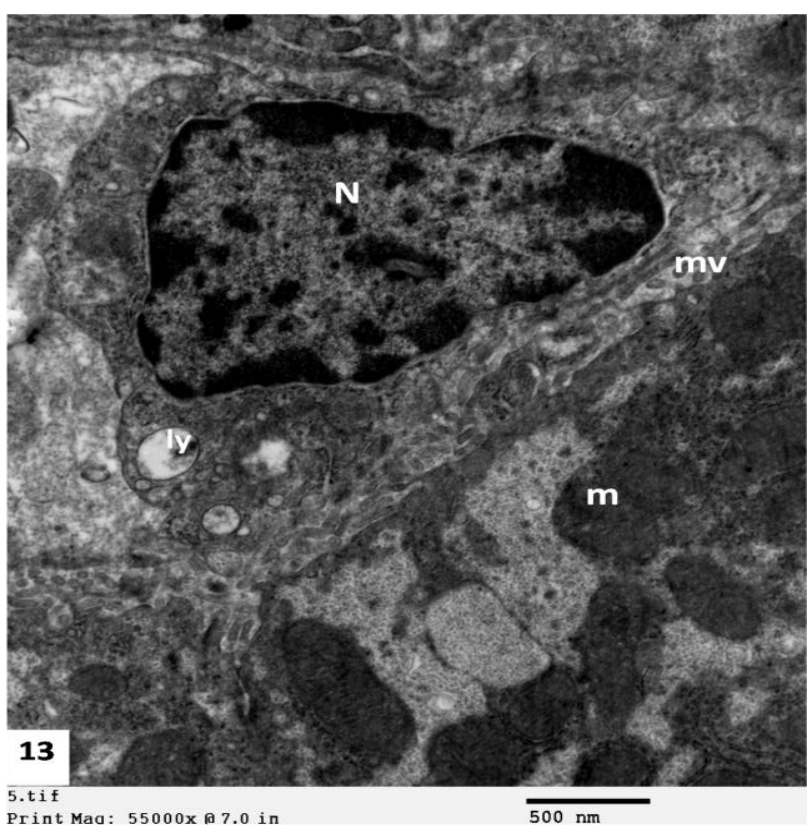

Figure 13:Electron micrograph of a control rat liver, showing a Kupffer cell (K) lining the blood sinusoid. It has a heterochromatic nucleus $(\mathrm{N})$ and few lysosomes (ly). Part of a hepatocyte is seen with many microvilli (mv) protruding into the space of Disse. m; mitochondria.

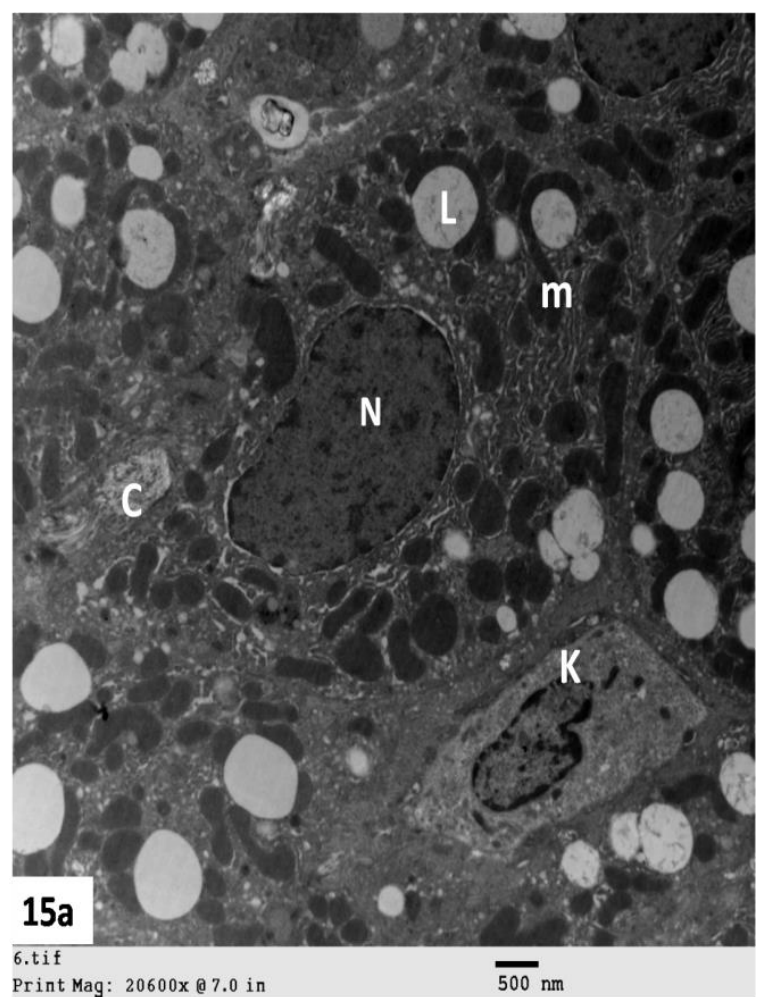

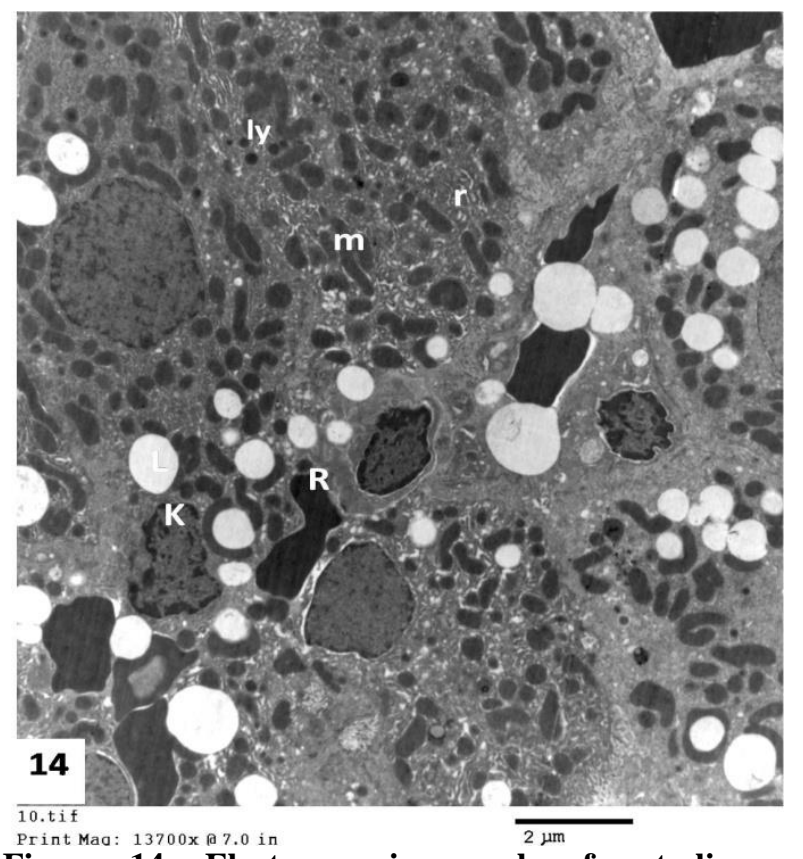

Figure 14: Electron micrograph of rat liver of acetaminophen group II, revealing hepatocytes with many lipid droplets $(\mathrm{L})$. The cytoplasm reveals many mitochondria with dense matrix $(\mathbf{m})$, mildly dilated profiles of rough endoplasmic reticulum $(r)$ and some lysosomes (ly). Note the presence of some Kupffer cells (k) lining congested blood sinusoids. R; red blood cell.

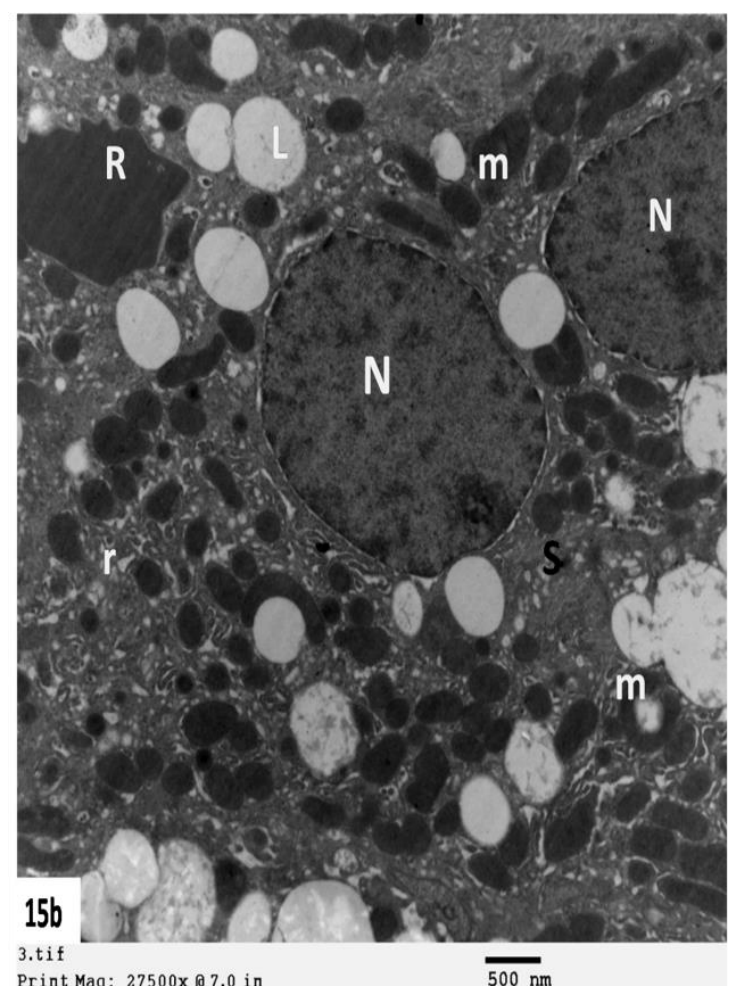

Figure 15 (a \& b): Electron micrographs of hepatocytes of acetaminophen group II rats, showing many lipid droplets $(\mathrm{L})$ and mitochondria with dense matrix $(\mathrm{m})$. Mildly dilated profiles of rough $(\mathbf{r})$ and smooth (S) endoplasmic reticulum are seen. The nuclei $(\mathrm{N})$ of a binucleated hepatocyte show wide perinuclear cisternae. K; Kupffer cells, $\mathbf{C}$; collagen, R; extravasated red blood cell. 


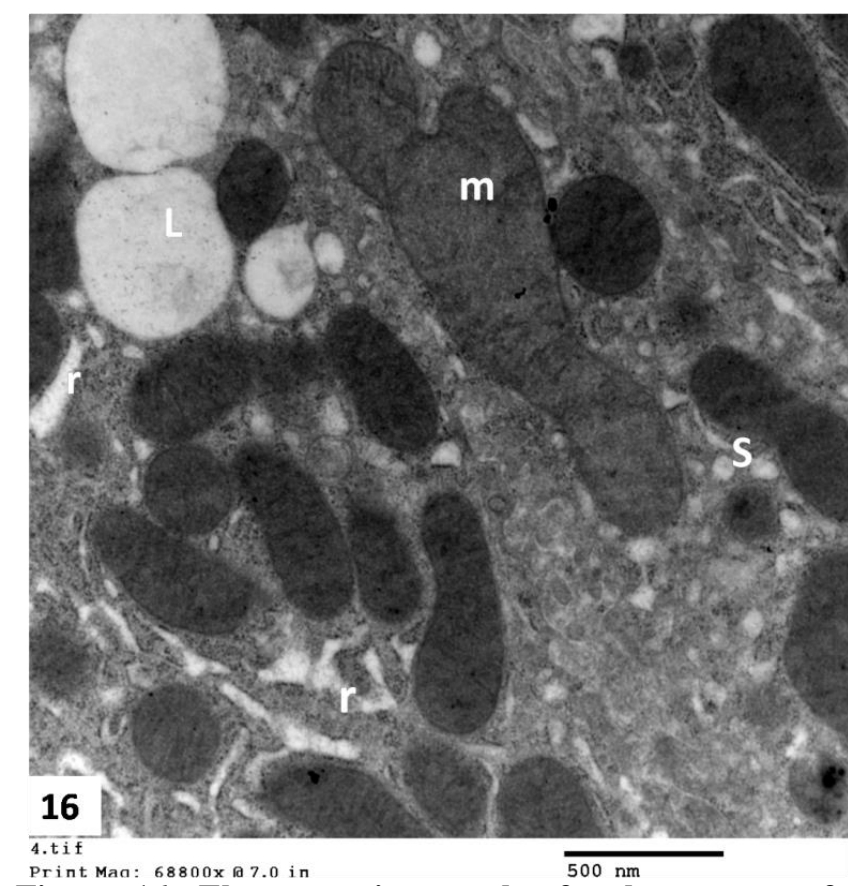

Figure 16: Electron micrograph of a hepatocyte of acetaminophen group II rats, showing a giant bizarre shaped mitochondrion (m), dilated and partially degranulated rough endoplasmic $(r)$ and dilated smooth endoplasmic reticulum (S). L; lipid droplet.

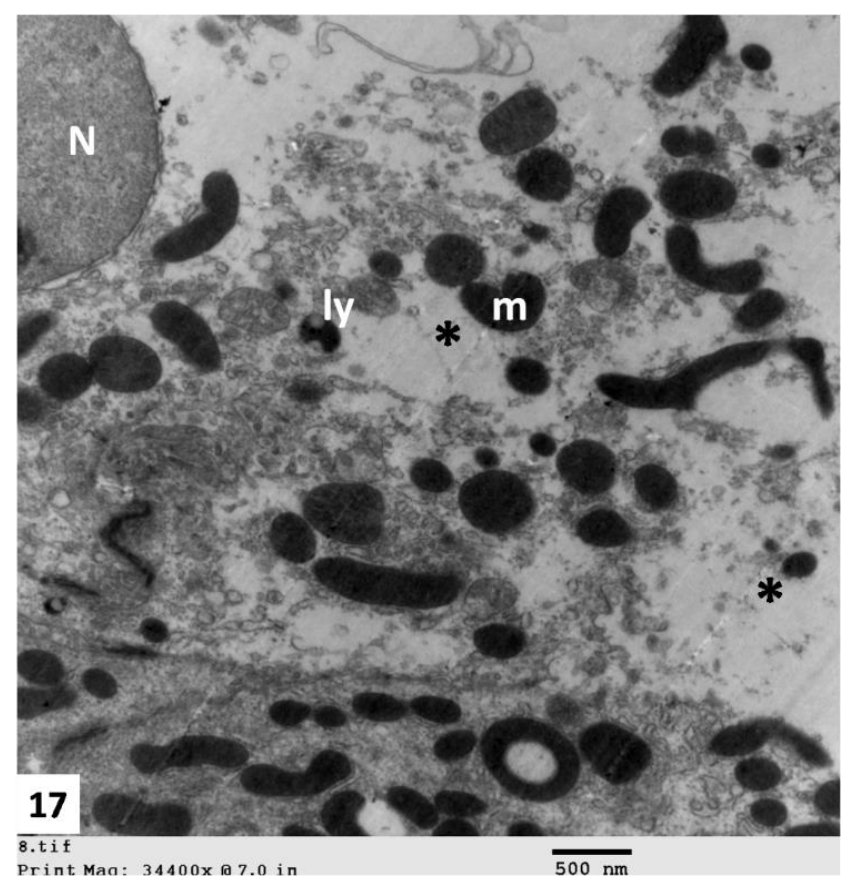

Figure 17: Electron micrograph of rat liver of acetaminophen group II showing a hepatocyte with large areas of rarified cytoplasm (*) and dense mitochondria (m). N; nucleus, ly; lysosomes.
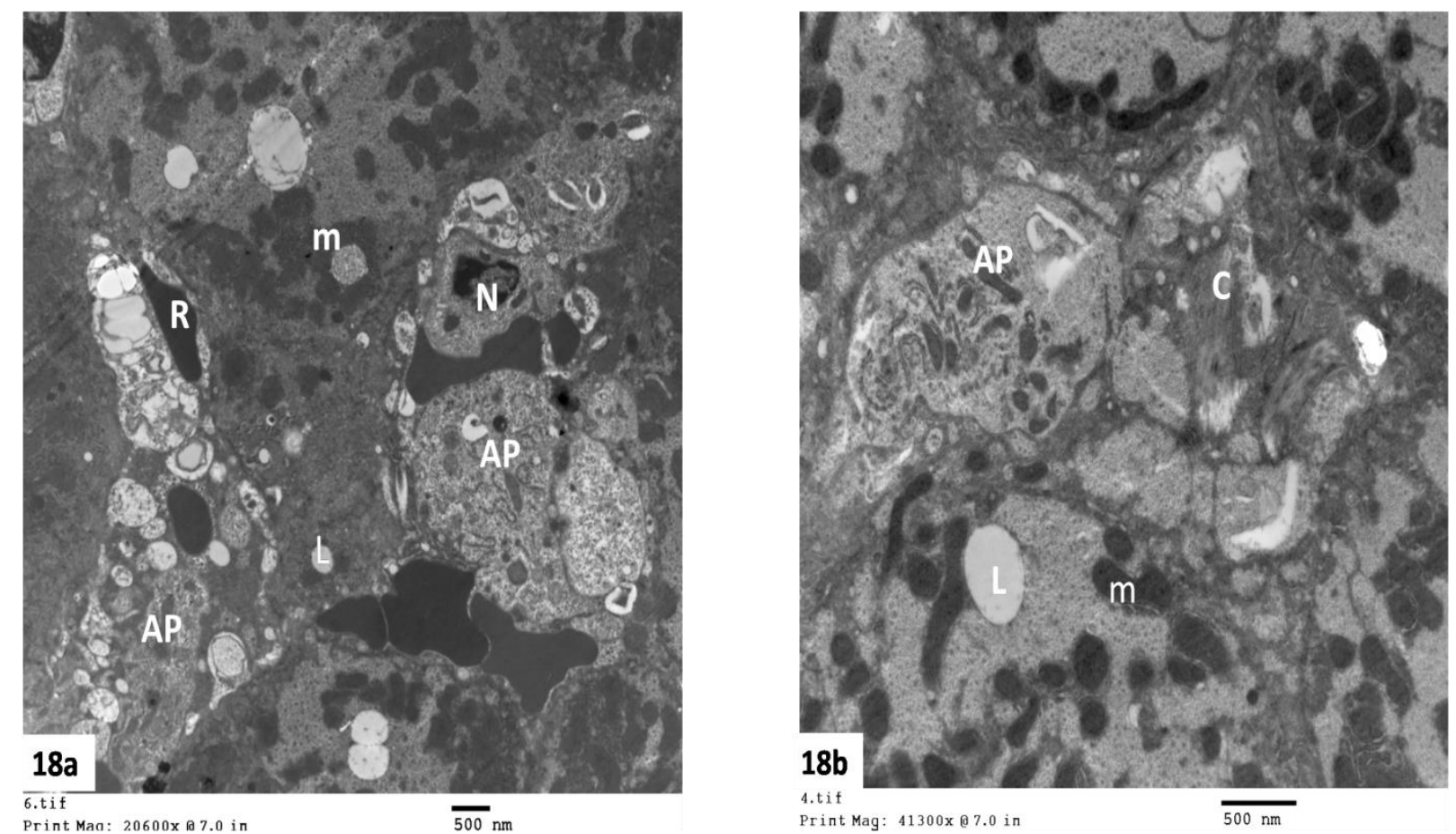

Figure $18(a \& b)$ : Electron micrographs of rat liver of acetaminophen group II, showing multiple apoptotic bodies (AP) with dense cytoplasmic organelles. The adjacent hepatocytes show pleomorphic mitochondria with dense matrix $(\mathrm{m})$ and lipid droplets $(\mathrm{L}) . \mathrm{R}$; red blood cell, $\mathrm{N}$; nucleus, $\mathrm{C}$; collagen fibers in the perisinusoidal space. 


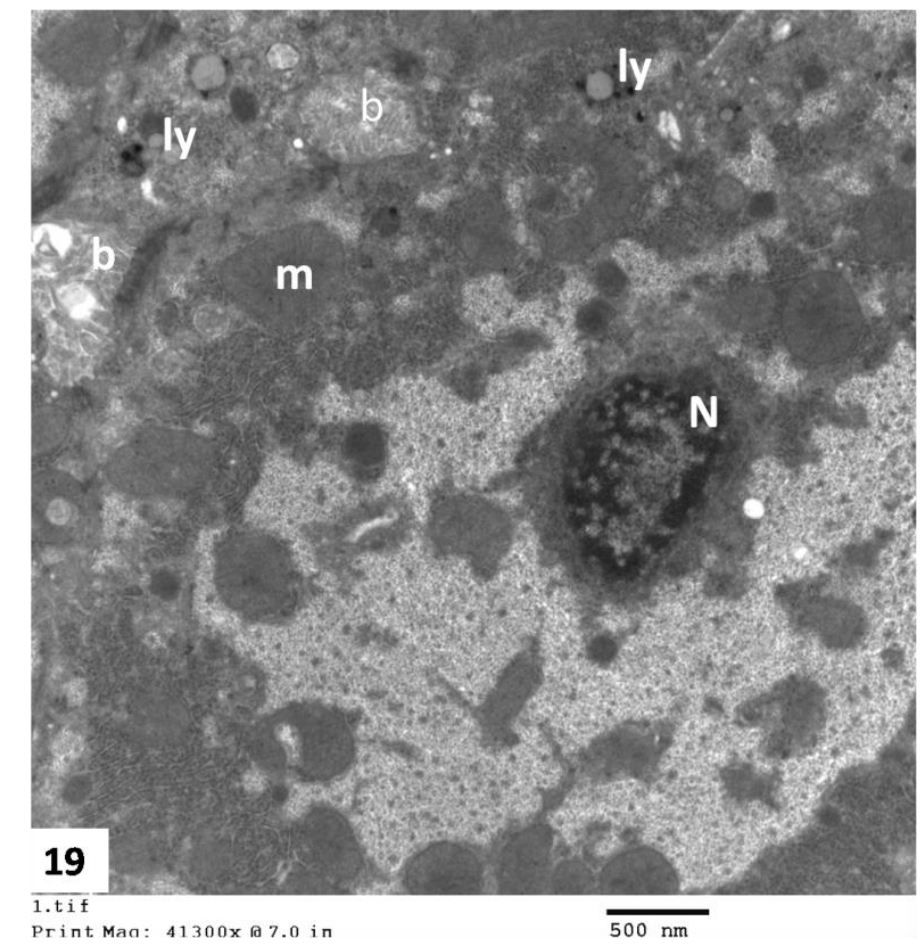

Figure 19: Electron micrograph of acetaminophen group II rat liver, revealing markedly affected hepatocyte with a small dense nucleus with peripheral heterochromatin clumps (N). The cytoplasm shows crowded organelles around the nucleus and towards the periphery of the cell. Many lysosomes (ly) are also seen. Note, dilated bile canaliculi (b). m; mitochondria.
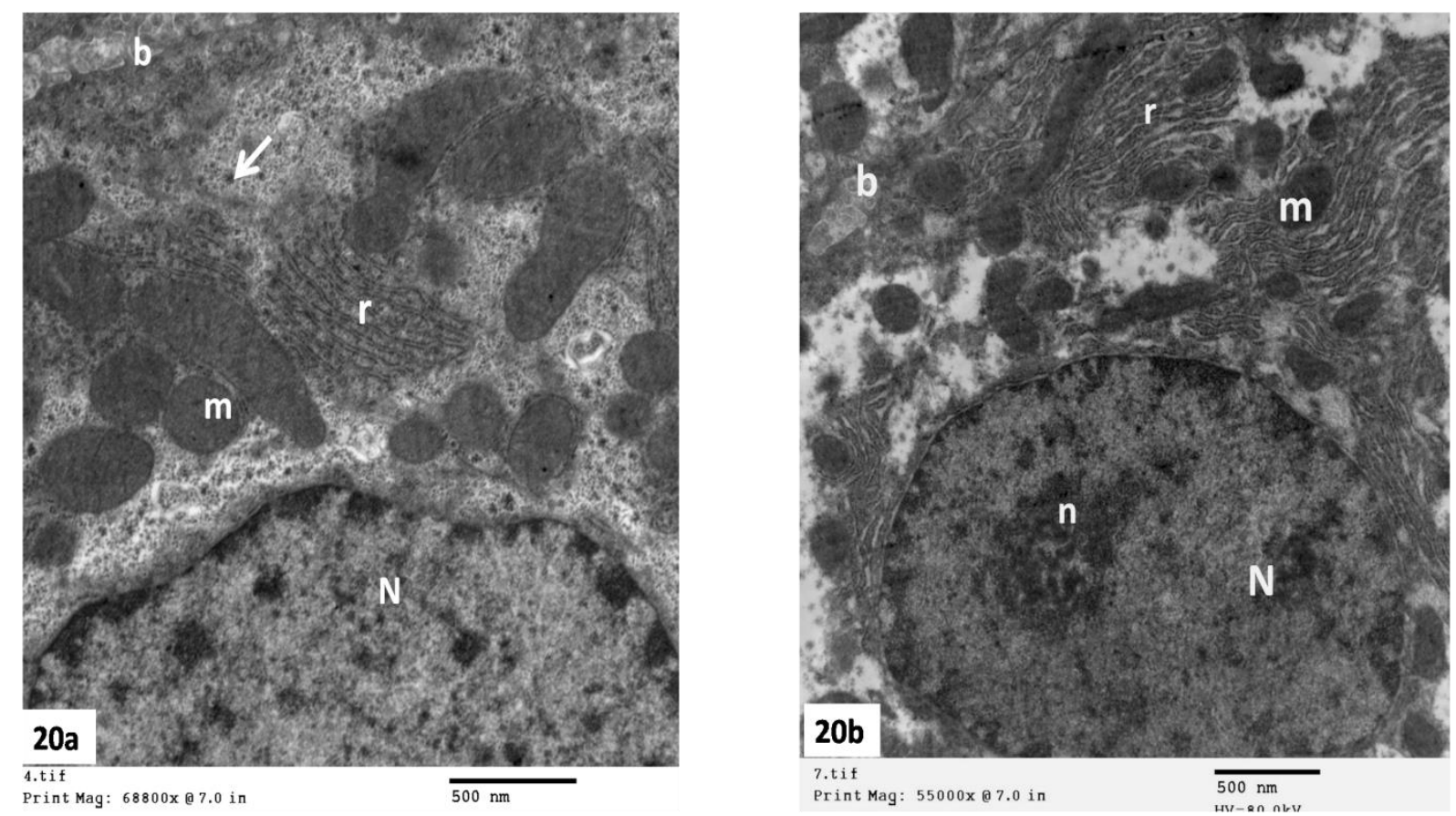

Figure 20 (a \&b): Electron micrographs of rat liver of subgroup IIIa (acetaminophen+ NAC), showing hepatocytes with euchromatic nuclei $(\mathrm{N})$, parallel arrays of rER (r) and numerous mitochondria (m). b; bile canaliculus, (arrow); glycogen granules, n; nucleolus. 


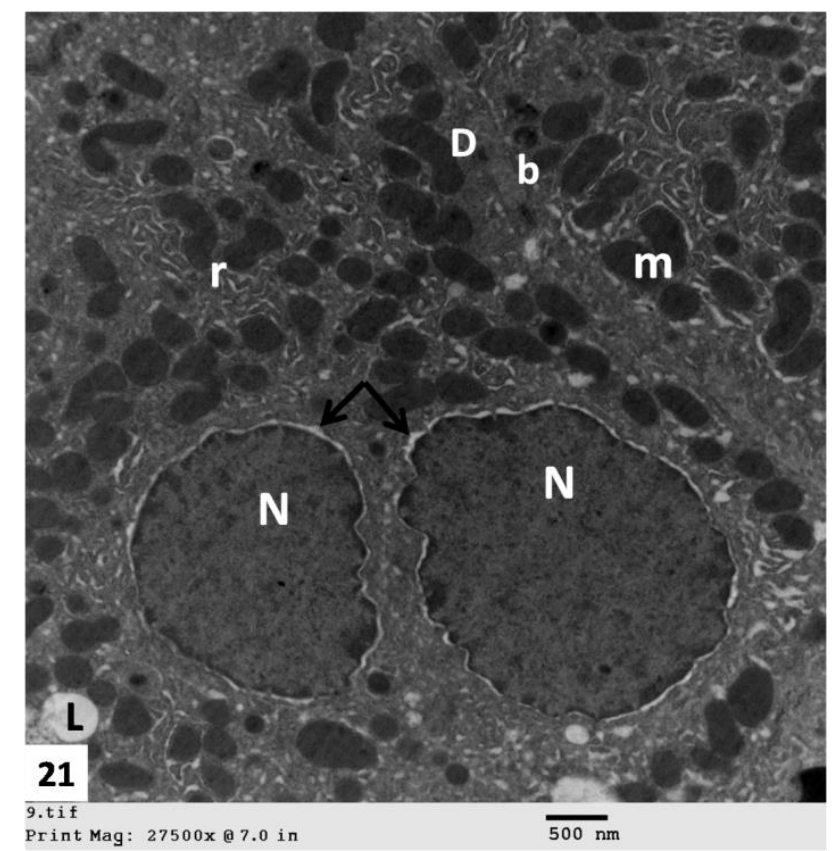

Figure 21: Electron micrograph of rat liver of subgroup IIIa (acetaminophen+ NAC), showing a binucleated hepatocyte with irregular euchromatic nuclei (N). The cytoplasm contains numerous mitochondria (m) with dense matrix and dilated rough endoplasmic reticulum (r). Note, dilated perinuclear cisternae (arrow). b; bile canaliculus, D; desmosomes, L; lipid droplet.
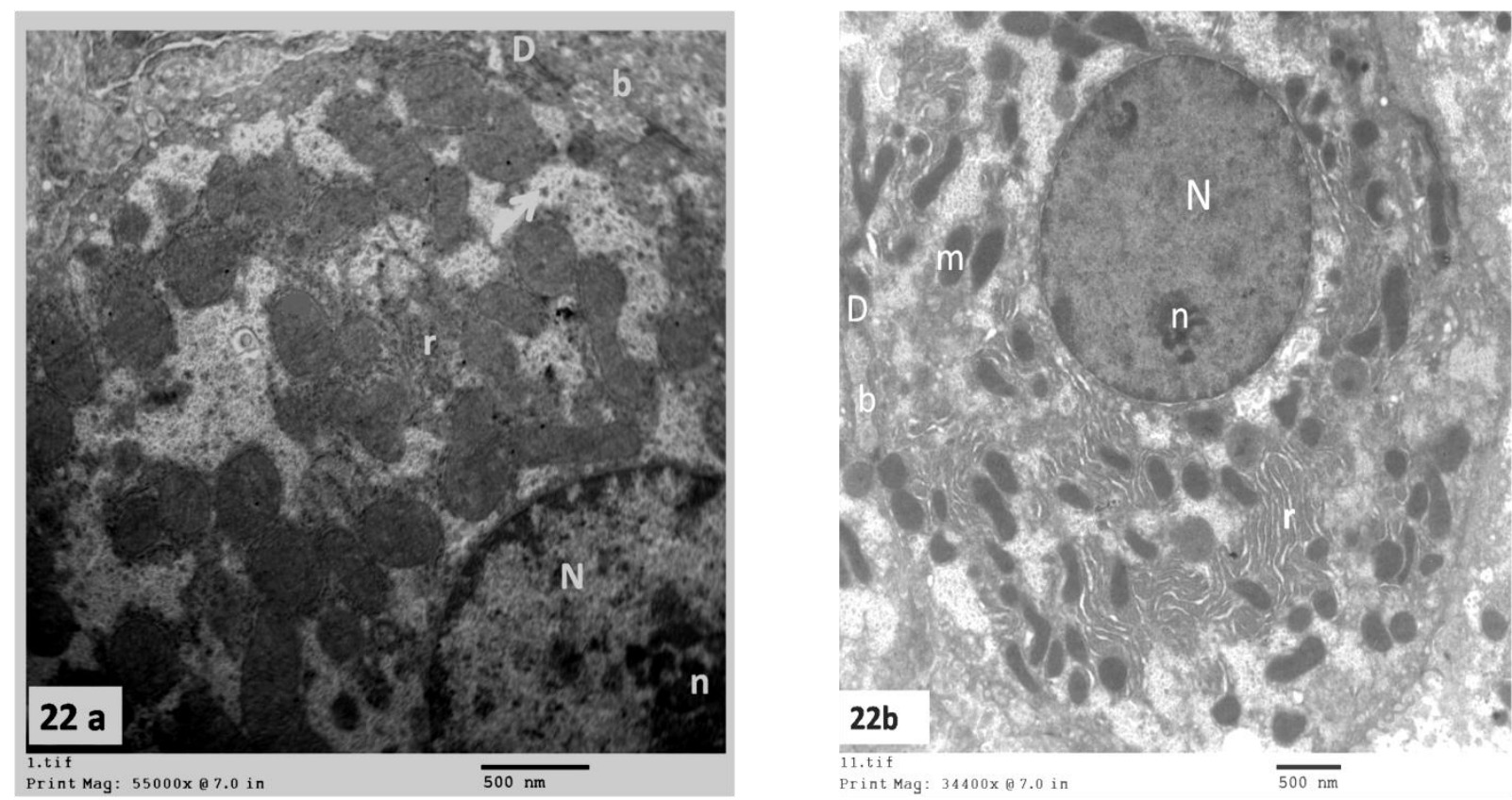

Figure 22 (a \&b):Electron micrograph of rat liver of subgroup IIIb (acetaminophen+ NAC), showing hepatocytes with euchromatic nuclei $(\mathrm{N})$ and prominent nucleoli (n). Their cytoplasm shows parallel arrays of rough endoplasmic reticulum (r) and glycogen granules (arrow). One cell reveals mitochondria with dense matrix (m). b; bile canaliculus, D; desmosomes 


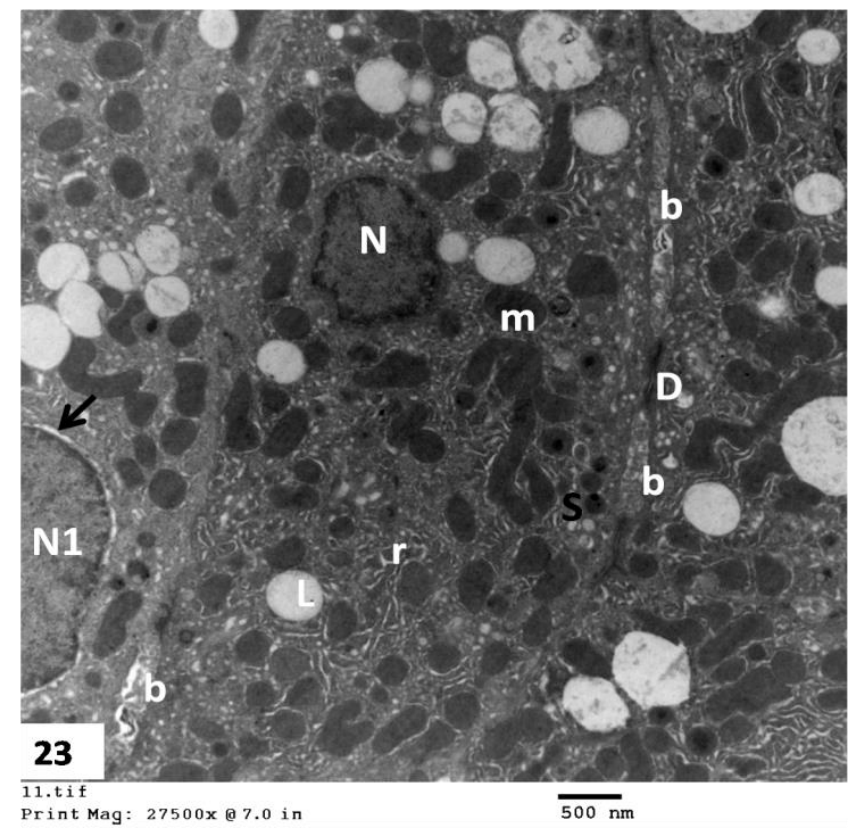

Figure 23: Electron micrographs of rat liver of subgroup IIIb (acetaminophen +CoQ10), showing group of hepatocytes with slightly irregular nuclei $(\mathrm{N})$, one of them (N1) exhibits wide perinuclear cistern (arrow). Their cytoplasm shows many lipid droplets $(\mathrm{L})$, mildly dilated rough (r) and smooth (S) endoplasmic reticulum. Notice: dilated bile canaliculi (b). m; mitochondria, D; desmosomes.
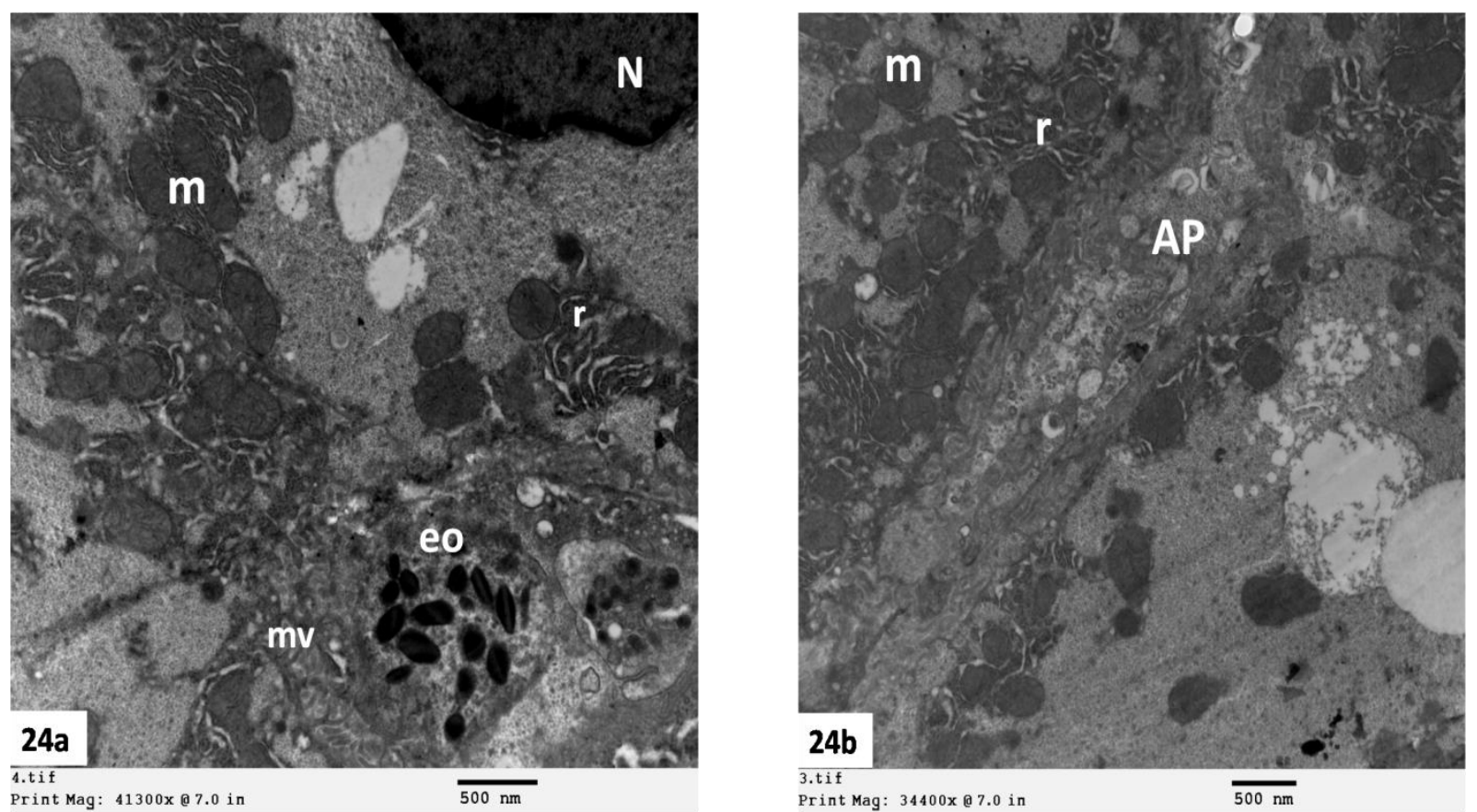

Figure 24 (a \&b): Electron micrographs of rat liver of subgroup IIIb (acetaminophen +CoQ10), showing hepatocytes with mildly dilated rough endoplasmic reticulum (r) and some lipid droplets (L). A perisinusoidal space containing microvilli of the adjacent hepatocytes ( $\mathrm{mv}$ ) and an eosinophil (eo) is seen. Notice the presence of apoptotic body (AP). m; mitochondria, N; nucleus. 


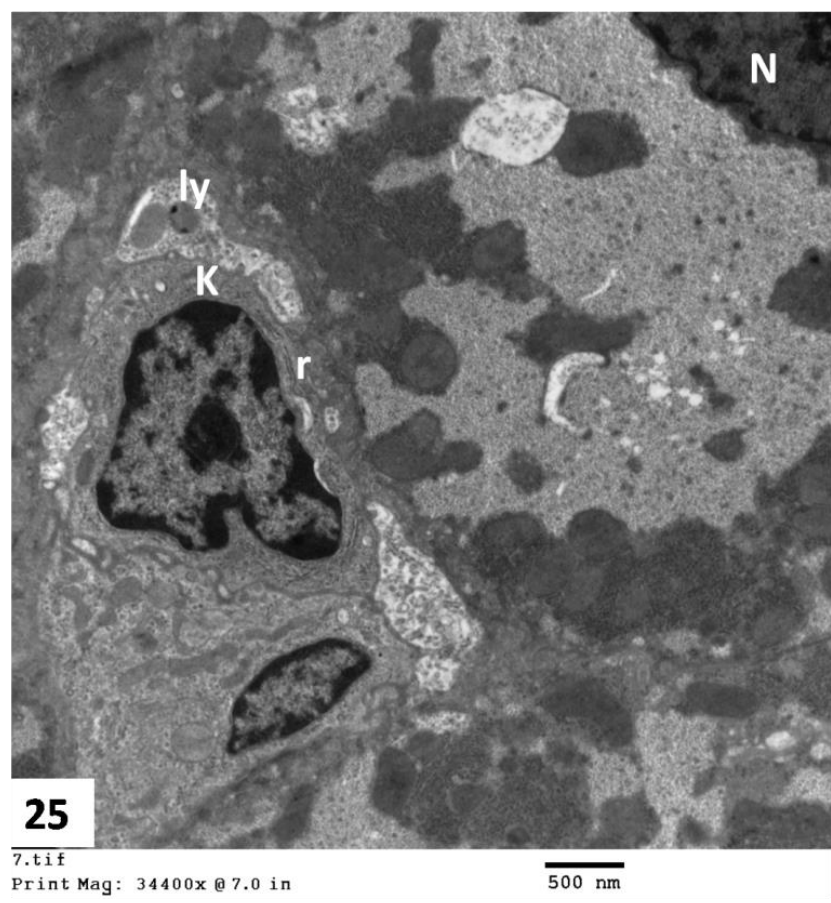

Figure 25: Electron micrograph of rat liver of subgroup IIIb (acetaminophen +CoQ10), showing a Kupffer cell (K) lining the blood sinusoid. Its cytoplasm shows arrays of rough endoplasmic reticulum (r). $\mathrm{N}$; irregular heterochromatic nucleus.

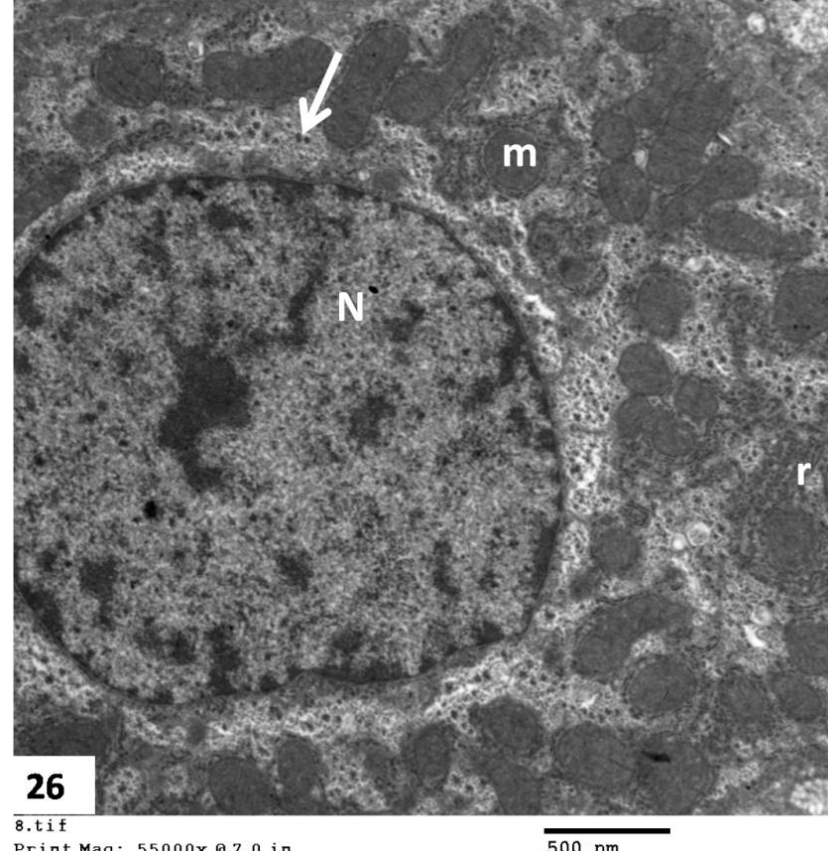

Print Mag: $55000 x$ a 7.0 in

Figure 26: Electron micrograph of rat liver of subgroup IIIc (acetaminophen + Aloe vera), showing a hepatocyte with euchromatic nucleus $(\mathrm{N})$, parallel arrays of rER (r) and numerous mitochondria (m). (arrow); glycogen granules.

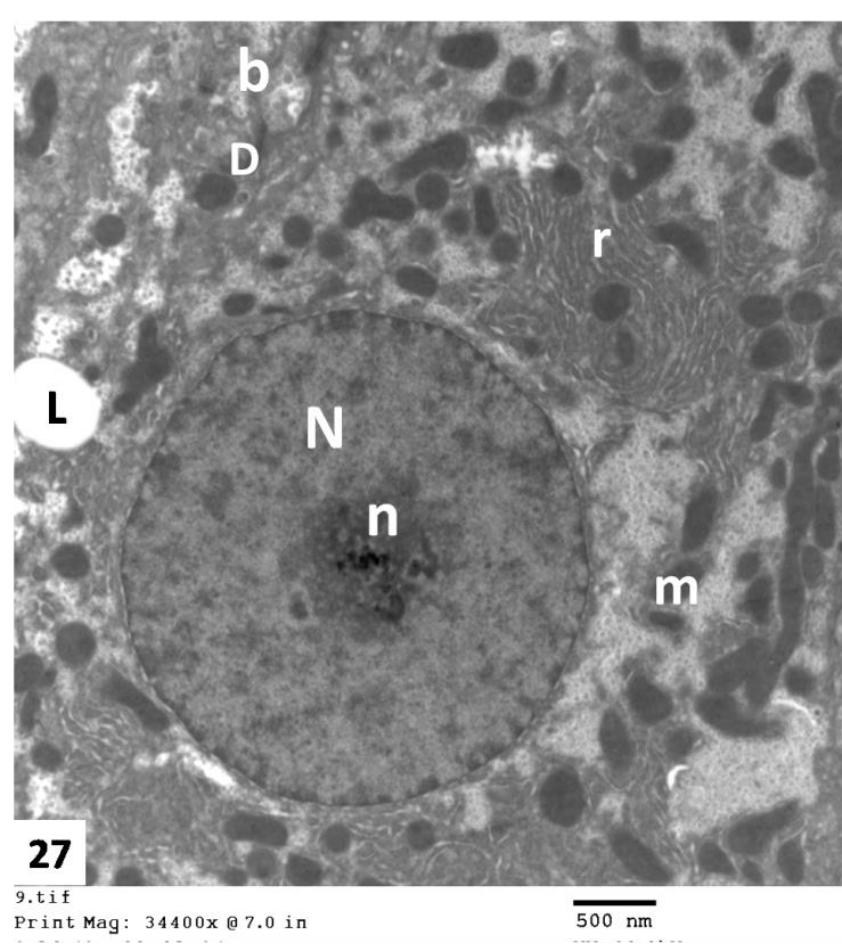

Figure 27:Electron micrograph of rat liver of subgroup IIIc (acetaminophen + Aloe vera), showing a hepatocyte with euchromatic nucleus $(N)$ of regular outline and visible nucleolus (n). The cytoplasm shows parallel arrays of rough endoplasmic reticulum (r), numerous mitochondria with dense matrix (m). L; lipid droplet, b; bile canaliculus, D; desmosomes.

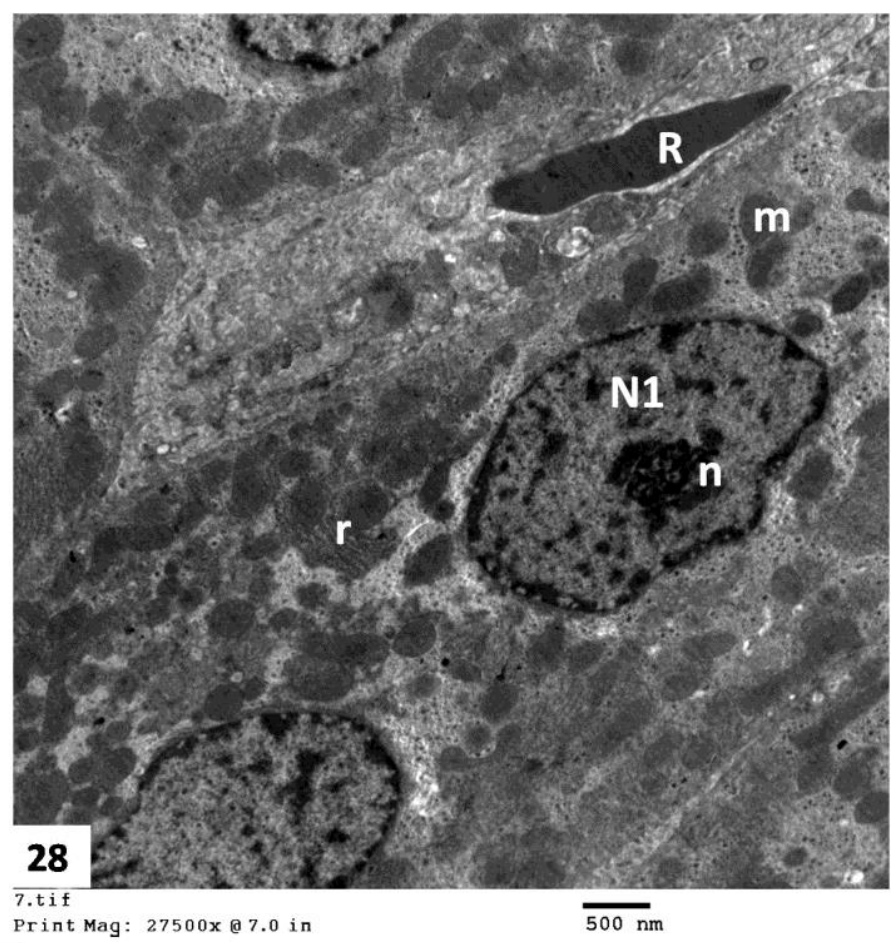

Figure 28: Electron micrograph of rat liver of subgroup IIIc (acetaminophen + Aloe vera), showing a binucleated hepatocyte with euchromatic nuclei and one of them (N1) with prominent nucleolus (n). Its cytoplasm contains arrays of rough endoplasmic reticulum (r) and numerous mitochondria $(\mathrm{m}) . \mathrm{R}$; red blood cell. 


\section{Discussion}

Acetaminophen (APAP) is a widely used over-thecounter analgesic antipyretic drug. Severe liver injury occurs in experimental animals and humans in cases of overdose, the incidence of which is increasing (Salminen et al 2012). Sometimes even therapeutic doses of APAP cause hepatic damage if there is any associated risk factors. APAP toxicity whether by intentional ingestion, non-intentional misuse, and repeated supra-therapeutic misuse remains the most common cause of drug-induced liver failure (Algren 2008).

It is thought that the target organ for APAP toxicity is the liver because this is the primary site where the detoxification of the drug takes place. Animal models especially rats and mice have played a great role in studying the toxic effects of APAP, mechanisms of toxicity and examining the chemicals that potentiate or protect from this toxicity. $\mathrm{LD}_{50}$ value of APAP for rats is much higher than $\mathrm{LD}_{50}$ of mice as mice are much more sensitive (Wexler et al 2005). So, rats were the best choice for screening of the possible hepatoprotective drugs.

$\mathrm{N}$-acetylcysteine (NAC) has been used in clinical practice for several decades as a mucolytic agent and for the treatment of multiple disorders such as doxorubicin-induced cardiotoxicity, acute respiratory distress syndrome and heavy metal toxicity (Samuni et al 2013). It is the standard therapy for acute Acetaminophen toxicity and although oral and intravenous NAC are well tolerated but oral administration is commonly associated with nausea and vomiting while intravenous administration has been associated with the development of anaphylactic reactions generally characterized by mild rash or urticaria that typically respond to antihistamines. Lifethreatening anaphylactic reactions and deaths are uncommon but have been reported (Algren 2008).

Coenzyme Q10 (CoQ10) is a compound found naturally in the human body. It is a cofactor in the electron-transport chain, the series of redox reactions that are involved in the synthesis of adenosine triphosphate (ATP). Since the body's major form of stored energy is ATP and most cellular functions are dependent on its adequate supply, CoQ10 is essential for the health of virtually all human tissues and organs (Ikematsu et al 2006).

Traditional herbal drugs have a great demand in underdeveloped countries due to their efficacy, low cost and lesser adverse effects, and they are considered to be "natural". Aloe vera, one of the herbal drugs, is a tropical or subtropical plant with a long history of use in folk medicine for skin and other disorders that date back thousands of years. Scientific investigations on Aloe vera "nature's gift" have gained more attention over the last decades due to its reputable medicinal properties (Eshun and He 2004).

Both CoQ10 and Aloe vera have antioxidant and anti-inflamatory effects so they may be used as alternative antidotes for hepatoprotection against APAP without the known side effects of NAC. So this study was conducted to compare the possible hepatoprotective effects of CoQ10, Aloe vera gel and NAC against acute APAP induced hepatotoxicity in adult albino rats.

In the assessment of liver injury, the elevation of AST and ALT are commonly used as preclinical and clinical markers for hepatocellular necrosis. Therefore, the serum levels of these enzymes are useful quantitative markers of the extent and type of hepatocellular damage (Ferah et al 2013). Another possible marker of liver injury by oxidative stress is MDA which is one of the important end products of lipid peroxidation. Its tissue level is an important indicator of the degree of lipid peroxidation in tissues, especially hepatocytes (Saoudi and El Feki, 2012). Decrease in the serum activity of SOD is a sensitive index in hepatocellular damage and is the most sensitive enzymatic index in hepatic injury (Ferah et al., 2013). GSH contains sulfhydryl donor groups and can act as a powerful intracellular reducing agent and antioxidant (Waring 2012).

Biochemically and histologically, groups Ib, Ic and Id revealed almost the control pattern of liver and the control level of enzymes similar to group Ia. This denotes that NAC, CO Q10 and Aloe vera are generally considered safe in therapeutic doses.

Examination of Group II rats (acetaminophen group) biochemically, showed significant elevation of AST, ALT and MDA along with depletion of liver GSH and significant decrease in level of SOD. Histological examination of liver sections showed loss of architecture with evidence of centrilobular necrosis of hepatocytes. Most hepatocytes appeared swollen with cytoplasmic vacuolation and dark nuclei especially at the centrilobular areas. Ultrastructurally, nuclei were irregular, shrunken and electron dense. The cytoplasm of most hepatocytes showed marked fatty infiltration, dense irregular nuclei and pleomorphic mitochondria with dense matrix. Some giant mitochondria were encountered as well. Apoptotic bodies containing aggregated cytoplasmic organelles were frequently seen. Therefore, the elevated levels of AST and ALT in the study might be attributed to the hepatocyte damage or loss of functional integrity of the cell membrane in the liver, indicating the severity of hepatocellular damage induced by APAP. The present findings were in accordance with several researchers who reported significant elevation of AST, ALT and MDA, depletion of GSH and centrilobular necrosis histologically (Wu et al 2010; Ayaz et al 2012; Fouad and Jresat, 2012).

There are two predominant theories for APAP to cause cell death, the first is the oxidative stress theory where APAP metabolites cause oxidative stress in the cell finally resulting in its death. The second theory is the covalent binding theory where the binding of the highly reactive metabolites of APAP to cell macromolecules causes cell death. APAP in therapeutic 
dose is metabolized into inactive metabolites while oxidation by cytochrome $\mathrm{P}-450$ system is a minor route that results in formation of $\mathrm{N}$-Acetyl-P-benzoquinone Imine (NAPQI) that is detoxified in the liver consuming the GSH. With overdosing, saturation of these pathways occurs and a larger proportion of the drug undergoes oxidation resulting in NAPQI which depletes GSH and binds to the sulphydryl (SH-) groups of cellular proteins causing cell injury and subsequent hepatic damage (Anoush et al 2009 and Ferner et al 2011).

Following toxic APAP doses and after NAPQI formation in increased amount occurs, GSH concentrations may be very low in the centrilobular cells, and GSH peroxidase which is the major enzyme of peroxide detoxification is expected to be inhibited. This coincides with the results of the present study that revealed significant reduction in GSH in group II and the centrilobular severity of histological changes. Glutathione depletion is one of a cascade of intracellular events which includes mitochondrial oxidative stress, generation of reactive nitrogen and oxygen species and activation of stress proteins and gene transcription mediators (Hodgman and Garrard 2012). After depletion of GSH, NAPQI binds to critical cellular proteins which causes formation of peroxynitrite and ROS inside mitochondria and subsequent hepatic necrosis (Jaeschke and Ramachandran 2011).

It has been reported that the cytotoxicity of NAPQI was dependent upon its metabolism through one electron reduction followed by re-oxidation thus generating reactive oxygen species (ROS) (Zhao et al 2011). Three different mechanisms have been proposed to account for the increased level of ROS: uncoupled CYP2E1 or other enzymes, activated NADPH oxidase, and mitochondrial uncoupling. Zone 3 liver cells which are rich in CYP2E1, are most susceptible to injury and this results in the characteristic centrilobular pattern of hepatic necrosis seen with APAP toxicity (Hodgman and Garrard 2012).

Lipid peroxidation, mediated by ROS, is believed to be an important cause of damage to cell membranes, because polyunsaturated fatty acids of the cellular membranes are degraded by this process (Zhao et al 2011). This is a well-known hypothesis to clarify massive cell death after APAP overdose and explains the ballooning and cellular vacuolations depicted in acetaminophen group (Jaeschke et al 2011).

The pathway for drainage of bile was interrupted by the death of hepatocytes and dissolution of their bile canaliculi thus the bile ductule penetrates in the injured parts of the lobule to establish the pathway. Toxins caused oxidative stress in the liver resulted in biliary duct proliferation which might be due to increased mitotic activity in the bile ductules and smaller bile ducts with the corresponding increase in their number (Kumar and Aster 2012).

James et al. (2003) have declared that APAP increases serum levels of nitrate plus nitrite, markers of nitric oxide (NO) synthesis. Increased NO formation occurs through up-regulation of inducible nitric oxide synthesis. NO reacts rapidly with superoxide leading to formation of the reactive intermediate peroxynitrite that is normally detoxified by GSH. Peroxynitrite nitrates tyrosine leading to formation of the unique biomarker 3 -nitrotyrosine which is biomarker of reactive nitrogen formation and nitrogen stress (Hinson et al 2010). Nitrotyrosine has been reported to be present together with APAP protein adducts in the centrilobular necrotic areas of the liver (Nagi et al 2010).

It has been proposed that NAPQI depletes cellular protein and non-protein thiols, which in turn leads to the inhibition of $\mathrm{Ca}^{+2}-\mathrm{Mg}^{+2}$ ATPase activity and disruption of $\mathrm{Ca}^{+2}$ homeostasis, resulting in hepatocellular necrosis (He et al 2012). Oxidative stress together with increased $\mathrm{Ca}^{+2}$ levels induces the mitochondrial membrane permeability transition (MPT). The MPT is characterized by uncoupling of the oxidative phosphorylation, mitochondrial swelling and formation of pores in the inner mitochondrial membrane whose opening allows the passage of solutes of large molecular weight. As a consequence, collapse of the mitochondrial membrane potential, the inability to synthesize ATP and further release of mitochondrial proteins will finally lead to necrotic cell death. In addition, mitochondrial inter-membrane proteins endonuclease $\mathrm{G}$ and apoptosis-inducing factor translocate to the nucleus and cause nuclear DNA fragmentation (Jaeschke and Ramachandran 2011).

It has been demonstrated that APAP toxicity results in overexpression of p53 in liver cells whose induction mediates apoptosis through transcriptional up-regulation of target pro-apoptotic genes resulting finally in activation of the caspase family of proteases and apoptotic cell death. Oxidative stress with increased generation of ROS is correlated with p53 activation (Fouad and Jresat 2012). In addition caspase-3 protein expression in the hepatocytes was found to play an apoptotic effect in APAP-induced liver injury, and this might explain the presence of multiple apoptotic bodies (Wang et al 2010).

Increasing evidence suggests that inflammation plays a role in the process of chemicalinduced hepatotoxicity. It has been reported that APAP toxicity activates Kupffer cells which results in the release of an array of inflammatory cytokines, such as interleukins (IL-1, IL-6) and tumor necrosis factor alpha (TNF- $\alpha$ ). Kupffer cells release also NO and superoxide with increased peroxynitrite formation (Fouad and Jresat 2012). TNF- $\alpha$ is an important proinflammatory cytokine that exerts multiple functions in immunity, inflammation, control of cell proliferation, differentiation and apoptosis (Ferah et al 2013). Also ROS besides their direct damaging effects on tissues, trigger the accumulation of leucocytes, which further enhance the tissue injury when being activated (Zhao et al 2011) Moreover, TNF is known to recruit and activate other inflammatory cells. The c-Jun N-terminal kinases (JNKs), a subfamily of the mitogen-activated protein (MAP) kinases, become activated early in 
APAP toxicity. JNK activation may be mediated by ROS as well as by TNF- $\alpha$ and it may be a mechanism that is associated with the initiation of MPT (Hinson et al 2010).

Acetaminophen overdose leads to mitochondrial dysfunction resulting in deficient mitochondrial $\beta$-oxidation of fatty acids which is characterized by accumulation of abnormal amounts of fats mainly triglycerides and appearance of multiple small droplets of triglycerides within the hepatocytes. Triglyceride accumulation resulted from an imbalance between the rate of its synthesis and release by the parenchymal cells into the systemic circulation. The reduction of hepatic triglyceride lipase and lipoprotein lipase which are lipolytic enzymes, may lead to decreased removal of triglycerides from plasma and its accumulation in tissues. Triglyceridemia occurs frequently in hepatocellular diseases as described in viral and drug induced toxic hepatitis (Raja 2010).

The administration of different antidotes to the acute acetaminophen intoxicated animals resulted in obvious amelioration of hepatotoxicity, yet in variable grades that was more apparent histologically. In the present study administration of NAC after toxic APAP dose in subgroup IIIa rats significantly reversed APAP toxicity. Biochemically, NAC significantly decreased AST, ALT and MDA, repleted liver GSH and increased SOD level as compared to APAP group. Histologically, liver sections revealed preserved architecture of hepatic lobules. Many hepatocytes were binucleated but there were dilated central veins and cellular infiltration. Ultrastructurally, few cells showed moderate affection with their cytoplasm revealed mildly dilated rough endoplasmic reticulum and pleomorphic mitochondria with slightly dense matrix. These findings were in accordance with previous researches (Kaya et al 2008; Zembron-Lacny et al 2009; Acharya and Lau-Cam 2010).

NAC is regarded as the antidote of choice for treating APAP overdoses. The most accepted explanation for its protective actions is that it serves as a source of L-cysteine for GSH synthesis. It is reported to both replenish the depleted stores of GSH and act as a GSH substitute thus can conjugate directly with NAPQI facilitating its detoxification before initiating hepatic injury (Acharya and Lau-Cam 2010). When given shortly after APAP ingestion, NAC prevents toxicity by acting as a glutathione precursor while after NAPQI has covalently bound to hepatocellular protein; NAC modifies the subsequent toxin-induced inflammatory response. NAC may act directly as an antioxidant; act as a reservoir for thiol groups; increase nitric oxide synthase with increased formation of the potent vasodilator s-nitrosothiol thus improving blood flow; and increase formation of essential endogenous antioxidants such as GSH, tocopherol radicals and ascorbate. In this manner, NAC can modulate the oxidative stress and inflammatory cascade. The potent vasodilator s-nitrosothiol might be the cause of dilated central veins encountered in this group (Howland 2007 and Zembron-Lacny et al 2009).
NAC inhibits the activation of c-Jun Nterminal kinase, nuclear factor-kB and TNF- $\alpha$. Moreover, NAC has growth-promoting activities as it can prevent apoptosis and promote cell survival by activating extracellular signal-regulated kinase pathway, a concept useful for treating certain degenerative diseases. In such a context, San-Miguel B et al. reported that NAC protected the liver from apoptotic death in an animal model of fulminant hepatic failure, as the study of suggested a potential hepatoprotective role of NAC partially through the modulation of the intrinsic pathway of apoptosis (SanMiguel et al 2006). In addition, Sener et al. (2003) showed that NAC caused significant inhibition of MDA production and protein Oxidation probably in part by scavenging the very reactive hydrogen peroxide and lipid peroxyl radical. Thus, NAC treatment effectively protects the liver tissues against oxidative damage.

Administration of Co Q10 to subgroup IIIb rats after the toxic APAP dose significantly lowered AST, ALT and MDA when compared to group II. Also Co Q10 repleted liver GSH and increased SOD levels significantly when compared to the toxicity group thus reversing APAP toxicity. Histologically liver sections showed evident improvement as compared to group II. Nevertheless, focal areas of swollen hepatocytes with cytoplasmic vacuolation, cellular infiltration and congestion of some central veins as well as proliferation of bile ducts were encountered. Moderate ultrastructural changes of some hepatocytes were evident. Some cells showed irregular nuclei with dilated rough endoplasmic reticulum and pleomorphic mitochondria with dense matrix. Apoptotic bodies with aggregated cytoplasmic organelles in blood sinusoids were also seen. These results were in accordance with Fouad and Jresat. (2012). Moreover, Faid, (2014) declared that administration of cauliflower and Q10 showed synergistic effect in improvement of antioxidant enzymes and liver function in APAP induced liver toxicity.

A great evidence indicates that CoQ10 treatment ameliorates oxidative stress as it inhibits the generation of ROS, prevents the reduction of GSH, suppresses lipid peroxidation and scavenges lipid peroxidation products during free radical reactions. It further prevents nitrative tissue stress and suppresses excess NO production. Moreover, it acts as an indirect stabilizer of $\mathrm{Ca}^{+2}$ channels thus decreasing its overload (Al-Attar 2010 and Esfahani et al 2013). CoQ10 is both a critical component of the mitochondrial respiratory chain and a powerful antioxidant. Thus, its hepatoprotective effect in APAP induced acute hepatotoxicity can be attributed to its antioxidant and anti-inflammatory activities and to its ability to inhibit the activation of the NF-kB signaling pathway that promotes the transcription of TNF- $\alpha$ and iNOS genes. CoQ10 also has anti-apoptotic effect as it prevents the over expression of p53protein and caspase-3, an 'executioner' of apoptosis, in hepatocytes. The reduced p53 and caspase-3 activities observed with CoQ10 
treatment might be due to its free radical scavenging activity, anti-inflammatory action with reduced TNF- $\alpha$ production, and attenuation of NF-kB expression (Fouad and Jresat 2012).

A study carried out by Al-Attar, (2010) suggested that CoQ10 possesses hypolipidemic effects in rats supplemented with high cholesterol diet. He attributed the reduction in the values of lipid profile levels to inhibition of hepatic cholesterol synthesis, redistribution of cholesterol from plasma to the liver by the cholesterol metabolizing enzyme systems in the liver and control of lipids utilization.

In the current study, rats treated with Aloe vera after toxic APAP dose (Subgroup IIIc) showed significant protection against APAP hepatotoxicity. It was evidenced by the decrease of AST, ALT and MDA levels, the repletion of liver GSH and the increase in SOD activity significantly when compared to the toxicity group. Such treatment was associated with a significant increase in liver GSH levels in comparison with NAC and Co Q10. Histologically, liver sections revealed preserved architecture of hepatic lobules with the hepatocytes arranged in cords radiating from the central vein and separated by blood sinusoids. It further revealed nearly normal ultrastructural pattern of hepatocytes.

The present findings were in agreement with those of Nayak et al, (2011) who attributed the hepatoprotective activity of Aloe vera to its antioxidant property. Several other studies have demonstrated the hepatoprotective activity of Aloe vera against various hepatotoxic agents as well as in diabetic hepatopathy (Kim et al 2009; Tabrizi and Mohajeri 2012; Cui et al., 2014). It exerts its protective effect through suppression of oxidative stress and free radicals, acceleration of lipolysis and inhibition of inflammatory response (Kim et al 2009 and Parmar et al 2010). A study conducted by Wang et al, (2004) demonstrated that Aloe vera polysaccharides exert its protective effect through the inhibition of apoptosis which is mediated by inhibition of pro-apoptotic protein expression and over expression of anti-apoptotic proteins with a subsequent inhibition of apoptosis and cell cycle disruption.

Studies have shown that there are many ingredients contained in Aloe vera with different medical advantages. Zinc, selenium, choline, inositol and acemannan are among the important ingredients (Agarwal and Dwived 2013). Zinc and selenium together with choline and inositol in Aloe vera gel, plus their antioxidant effect, they intervene to improve the elasticity and fluidity of hepatic cell membranes and their metabolic capacity, resolving a large part of the liver's functional difficulties. It has been observed that the continued use of Aloe vera results in a functional improvement of hepatic cells (Rowley et al 2010; Rogalska et al 2011; Messarah et al 2012). Furthermore, acemannan together with the liposoluble vitamins rapidly restore the hepatic activity of the cells previously compromised by inflammation (Agarwal and Dwived 2013).

Overall, this study showed that acetaminophen induced hepatotoxicity was reversed with each of NAC, coenzyme Q10 and Aloe vera. Thus, each of them has a significant hepatoprotective effect in acute acetaminophen toxicity that was best seen with NAC and Aloe vera and less with CoQ10.

\section{Refrences}

Acharya M and Lau-Cam CA (2010): Comparison of the protective actions of $\mathrm{N}$ - acetylcysteine, hypotaurine and taurine against acetaminophen-induced hepatotoxicity in the rat. J Biomed Sci; 17(1):S35.

Agarwal A and Dwivedi N (2013): Aloe vera: Magic or myth. SRM Journal of Research in Dental Sciences; 4(3):119.

Al-Attar AM (2010): Hypolipidemic Effects of Coenzyme Q10 in Experimentally Induced Hypercholesterolemic Model in Female Rats. American Journal of Pharmacology \& Toxicology; 5(1):14-23.

Algren DA (2008): Review of N-acetylcysteine for the treatment of acetaminophen (paracetamol) toxicity in pediatrics. Second Meeting of the Subcommittee of the Expert Committee on the Selection and Use of Essential Medicines Geneva.

Anoush M, Eghbal M, Fathiazad F, et al., (2009): The protective effects of garlic extract against acetaminophen-induced oxidative stress and glutathione depletion. Pak J Biol Sci; 12(10).

Antoine DJ, Jenkins RE, Dear JW, et al., (2012): Molecular forms of HMGB1 and keratin-18 as mechanistic biomarkers for mode of cell death and prognosis during clinical acetaminophen hepatotoxicity. J Hepatol; 56(5):1070-9.

Ayaz SA, Mahanand S and Khan SW (2012): Pelagia Research Library. Der Pharmacia Sinica; 3 (6):738-44.

Bancroft JD and Gamble M (2008): Theory and practice of histological techniques. 6 th ed: Elsevier Health Sciences.

Barile FA (2004): Acetaminophen, Salicylates, and Nonsteroidal Anti- Inflammatory Drugs (NSAIDs) In: Clinical toxicology principles and mechanisms. $1^{\text {st }}$ ed. USA: CRC press; 183-96.

Benzie IFF and Wachtel-Galor S (2011): Herbal Medicine: Biomolecular and Clinical Aspects. $2^{\text {nd }}$ ed. USA: CRC press Taylor \& Francis group.

Burke A, Smyth E and FitzGerald GA (2006): Analgesic-antipyretic agents; pharmacotherapy of gout. In: Goodman \& 
Gilman's The Pharmacological Basis of Therapeutics. 11th ed. USA: McGraw-Hill Companies; 671-716.

Carleton HM, Drury RAB and Wallington EA (1980): Carleton's histological technique: Oxford University Press.

Cui Y, Ye Q, Wang H, et al (2014): Hepatoprotective potential of Aloe vera polysaccharides against chronic alcohol induced hepatotoxicity in mice. J Sci Food Agric; 94(9):1764-71.

Esfahani SA, Esmaeilzadeh E, Bagheri F, et al., (2013): The Effect of Co-Enzyme Q10 on Acute Liver Damage in Rats, a Biochemical and Pathological Study. Hepat Mon; 13(8).

Eshun K and He Q (2004): Aloe vera: a valuable ingredient for the food, pharmaceutical and cosmetic industries - a review. Crit Rev Food Sci Nutr; 44(2):91-6.

Faid SM (2014): Effect of Combination of Cauliflower and Q10 on Liver Injury in Experimental Rats. WASJ; 30(1):10-6.

Ferah I, Halici Z, Bayir Y, et al., (2013): The role of infliximab on paracetamol-induced hepatotoxicity in rats. Immunopharmacol Immunotoxicol; 35(3):373-81.

Ferner RE, Dear JW and Bateman DN (2011): Management of paracetamol poisoning. BMJ; 342(9):d2218.

Fouad AA and Jresat I (2012): Hepatoprotective effect of coenzyme Q10 in rats with acetaminophen toxicity. Environ Toxicol Pharmacol; 33(2):158-67.

Fouad AA, Al-Mulhim AS et al., (2013): Therapeutic effect of coenzyme Q10 against experimentally-induced hepatocellular carcinoma in rats. Environ toxicol pharmacol; 35(1):100-8.

He M, Zhang S, Jiao Y, et al., (2012): Effects and mechanisms of rifampin on hepatotoxicity of acetaminophen in mice. Food Chem Toxicol; 50(9): 3142-9.

Hinson JA, Roberts DW and James LP (2010): Mechanisms of acetaminophen-induced liver necrosis. Handb Exp Pharmacol; 196: 369405.

Hodgman MJ and Garrard AR (2012): A review of acetaminophen poisoning. Crit Care Clin; 28(4):499-516.

Howland MA (2007): N-Acetylcysteine. In: Goldfrank's Manual of Toxicologic Emergencies. 8th ed. USA: The McGraw-Hill Companies; 301-4.

Ikematsu $\mathrm{H}$, Nakamura $\mathrm{K}$, Harashima $\mathrm{S}-\mathrm{i}$, et al., (2006): Safety assessment of coenzyme Q10 (Kaneka Q10) in healthy subjects: a double- blind, randomized, placebo-controlled trial. Regul Toxicol Pharmacol; 44(3):212-8.

Jaeschke H, McGill MR, Williams CD et al., (2011): Current issues with acetaminophen hepatotoxicity - a clinically relevant model to test the efficacy of natural products. Life sciences; 88(17):737-45.

Jaeschke H and Ramachandran A (2011): Reactive oxygen species in the normal and acutely injured liver. J Hepatol; 55(1):227.

James LP, McCullough SS, Lamps LW et al., (2003): Effect of $\mathrm{N}$-acetylcysteine on acetaminophen toxicity in mice: relationship to reactive nitrogen and cytokine formation. Toxicological sciences; 75(2):458-67.

Kaufmann P, Thompson JL, Levy G, et al., (2009): Phase II trial of CoQ10 for ALS finds insufficient evidence to justify phase III . Ann Neurol; 66(2):235-44.

Kaya H, Koc A, Sogut S, et al., (2008): The protective effect of $\mathrm{N}$-acetylcysteine against cyclosporine A-induced hepatotoxicity in rats. J Appl Toxicol; 28(1):15-20.

Kim K, Kim H, Kwon J, et al., (2009): Hypoglycemic and hypolipidemic effects of processed Aloe vera gel in a mouse model of non-insulindependent diabetes mellitus. Phytomedicine; 16(9):856-63.

Kim SH, Cheon HJ, Yun N, et al., (2009): Protective effect of a mixture of Aloe vera and Silybum marianum against carbon tetrachlorideinduced acute hepatotoxicity and liver fibrosis. J Pharmacol Sci; 109: 119-127.

Kumar V AA and Aster JC (2012): Robbins basic pathology. 9th ed. philadelphia: Saunders.

McGill MR, Williams CD, Xie Y, et al., (2012): Acetaminophen-induced liver injury in rats and mice: comparison of protein adducts, mitochondrial dysfunction, and oxidative stress in the mechanism of toxicity. Toxicol Appl Pharmacol; 264(3):387-94.

Messarah M, Klibet F, Boumendjel A, et al., (2012): Hepatoprotective role and antioxidant capacity of selenium on arsenic-induced liver injury in rats. Exp Toxicol Pathol; 64(3):167-74.

Moron MS, Depierre JW and Mannervik B (1979): Levels of glutathione, glutathione reductase and glutathione $S$ transferase in rat lung and liver. Biochim Biophys Acta; 582:67-8.

Nagi MN, Almakki HA, Sayed-Ahmed MM, et al., (2010): Thymoquinone supplementation reverses acetaminophen-induced oxidative stress, nitric oxide production and energy decline in mice liver. Food Chem Toxicol; 48(8):2361-5. 
Nayak V, Gincy T, Prakash M, et al., (2011): Hepatoprotective activity of Aloe vera Gel against Paracetamol Induced Hepatotoxicity in albino rats. Asian J Pharm Biol Res; 1(2):94-8

Oyanagui Y 1984. Reevaluation of assay methods and establishment of kit for superoxide dismutase activity. Anal biochem; 142(2):290-6.

Parmar S.R, Vashrambhai P.H and Kalia K (2010): Hepatoprotective activity of some plants extracts against paracetamol induced hepatotoxicity in rats. Journal of Herbal Medicine and Toxicology; 4: 101-106.

Raja B (2010): Preventive Effect of Syringic acid on Hepatic Marker Enzymes and Lipid Profile Against Acetaminophen-Induced Hepatotoxicity Rats. IJPBA; 1(4).

Reitman S and Frankel S (1957): A colorimetric method for determination of serum glutamicoxaloacetic and glutamic-pyruvic transaminases. Am J Clin Pathol; 28:56-63.

Rogalska J, Pilat-Marcinkiewicz B and Brzóska MM (2011): Protective effect of zinc against cadmium hepatotoxicity depends on this bioelement intake and level of cadmium exposure: A study in a rat model. Chem Biol Interact; 193(3):191-203.

Rowley T, McKinstry A, Greenidge E, et al., (2010): Antinociceptive and anti-inflammatory effects of choline in a mouse model of postoperative pain. Br J Anaesth; 105(2):201-7.

Sahu PK, Giri DD, Singh R, et al., (2013): Therapeutic and medicinal uses of aloe vera: a review. Pharmacology \& Pharmacy; 4:599.

Salminen WF, Yang X, Shi Q, et al., (2012): Green tea extract can potentiate acetaminophen-induced hepatotoxicity in mice. Food Chem Toxicol; 50(5):1439-46.

Samuni Y, Goldstein S, Dean OM et al., (2013): The chemistry and biological activities of $\mathrm{N}$ acetylcysteine. Biochim Biophys Acta (BBA)General Subjects; 1830(8):4117-29.

San-Miguel B, Alvarez M, Culebras J,et al., (2006): Nacetyl-cysteine protects liver from apoptotic death in an animal model of fulminant hepatic failure. Apoptosis; 11(11):1945-57.

Saoudi M and El Feki A (2012): Protective role of Ficus carica stem extract against hepatic oxidative damage induced by methanol in male wistar rats. Evid Based Complement Alternat Med; 2012:1-8.

Sener G, Sehirli AÖ and AyanosuSDülger G (2003): Protective effects of melatonin, vitamin $\mathrm{E}$ and $\mathrm{N}$-acetylcysteine against acetaminophen toxicity in mice: a comparative study. J Pineal Res; 35(1):61-8.
Subramanian KA, Manohar M and Mathan VI (1988): An unidentified inhibitor of lipid peroxidation in intestinal mucosa. Biochim Biophys Acta; 962:51-8

Tabrizi BA and Mohajeri D (2012): Protective effect of Aloe Vera Leaves Extract on Hepatic Tissue Injury in Streptozotocin-induced Diabetic Rats. Advances in Bioresearch; 3(3):67-73.

Titus R (2013): Aloe Vera- the magical plant amongst us. Online: Lulu press;. Available from: http://www.dpdotcom.com/freebie/Aloe $\% 20 \mathrm{~V}$ era\%20 Extract.

Tran UC and Clarke CF (2007): Endogenous synthesis of coenzyme Q in eukaryotes. Mitochondrion; 7:S62-S71.

Uehara T, Kosyk O, Jeannot E, et al., (2013): Acetaminophen-induced acute liver injury in HCV transgenic mice. Toxicol Appl Pharmacol; 266(2):224-32.

Visnagri A, Kandhare AD, Shiva Kumar V, et al., (2012): Elucidation of ameliorative effect of Co-enzyme Q10 in streptozotocin-induced diabetic neuropathic perturbation by modulation of electrophysiological, biochemical and behavioral markers. Biomedicine \& Aging Pathology; 2(4):157-72.

Wagner R (2007): Coenzyme Q10. Altern Med Rev; 12(2):159-68.

Wang A-Y, Lian L-H, Jiang Y-Z, et al., (2010): Gentiana manshurica Kitagawa prevents acetaminophen-induced acute hepatic injury in mice via inhibiting JNK/ERK MAPK pathway. World J Gastroenterol: WJG; 16(3):384.

Wang Z-W, Zhou J-M, Huang Z-S, et al., (2004): Aloe polysaccharides mediated radioprotective effect through the inhibition of apoptosis. J Radiat Res; 45(3):447-54.

Waring WS (2012). Novel acetylcysteine regimens for treatment of paracetamol overdose. Ther Adv Drug Saf; 3: 305-15.

Wexler P, Anderson B, Gad S, et al., (2005): Encyclopedia of toxicology. 2nd ed. USA: Elsevier Science Direct.

Wu Y-L, Jiang Y-Z, Jin X-J, et al., (2010): Acanthoic acid, a diterpene in Acanthopanax koreanum, protects acetaminophen-induced hepatic toxicity in mice. Phytomedicine; 17(6):475-9.

Zembron-Lacny A, Slowinska-Lisowska M, Szygula Z, (2009): The Comparison of Antioxidant and Hematological Properties of N-Acetylcysteine and $\alpha$-Lipoic Acid in Physically Active Males. Physiol Res; 58(6):855-61.

Zhao Y-L, Zhou G-D, Yang H-B, Wang J-B, et al., (2011): Rhein protects against acetaminopheninduced hepatic and renal toxicity. Food Chem Toxicol; 49(8):1705-10. 


\section{الملخص العربى}

\section{دراسة مقارنة للتأثير الوقائي المحتمل على الكبد لكل من إن-اسيتايل سيستيين ومساعد الانزيم كيو • 1 وجل نبات الصبر في التسمم الكبدى الحاد المحدث بالأسيتامينوفين في الجرذان البيضاء البالغة. (دراسة هستولوجية وبيوكيميائية)}

\section{هلى فؤاد عبدالسلام و هايدى مصطفي مجاهدو صفا عبد العزيز محمد ' و مني مصطفي صبحيخ و هالة محمود عبد المعطى"}

المقدمة:على الرغم من أن أستخدام الأسيتامينوفين (الباراسيتامول) علي نطاق واسع كمسكن وخحافض للحرارة الا أنه يعد الحساد

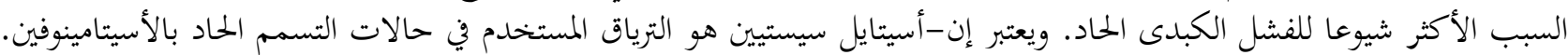

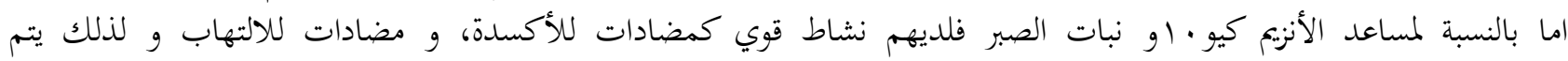
استخدامهما في العديد من المستحضرات الطبية.

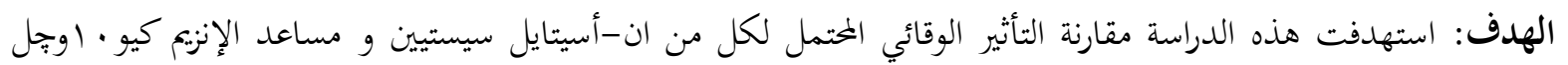

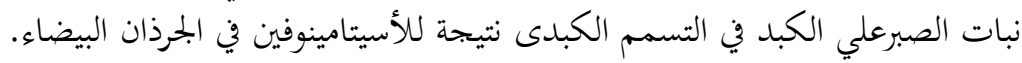

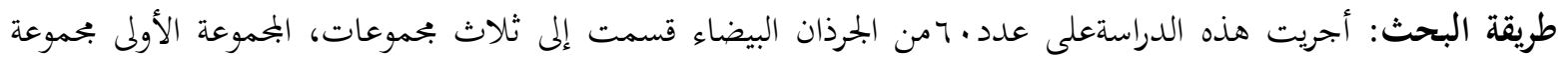

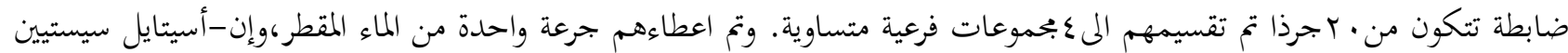

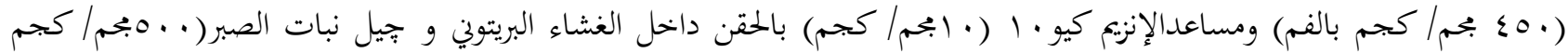

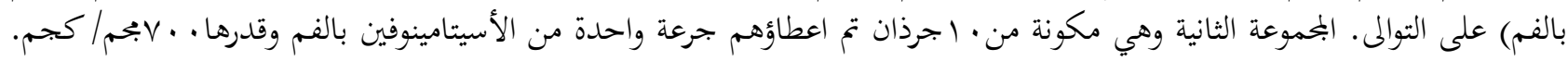

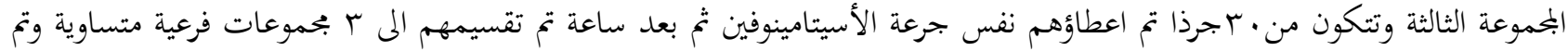

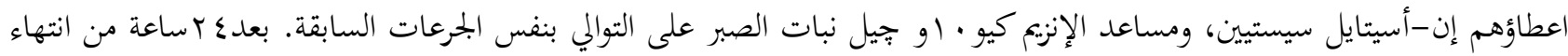

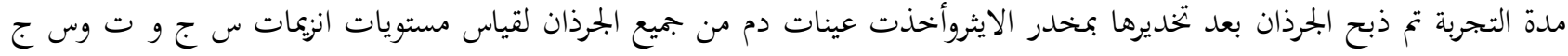

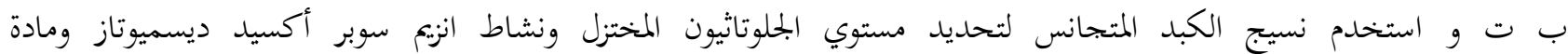

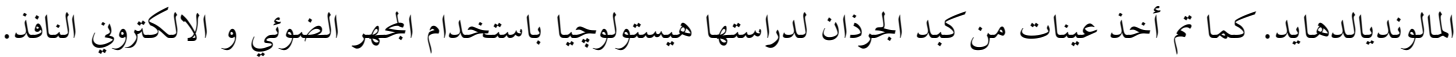

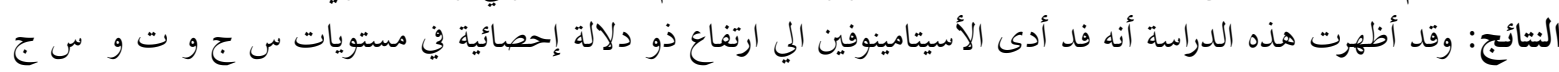

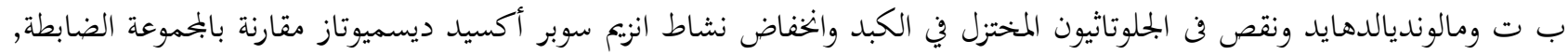

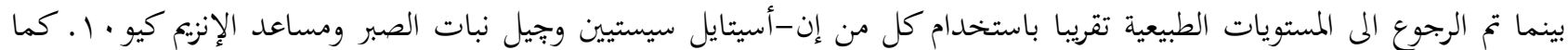

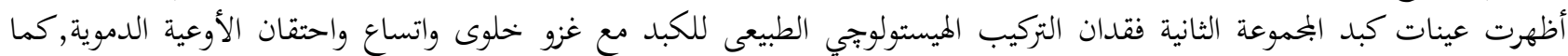

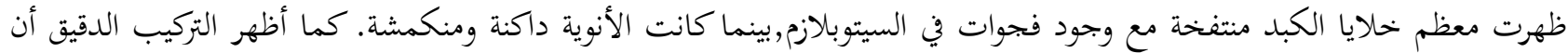

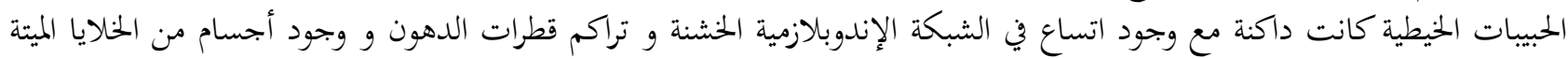

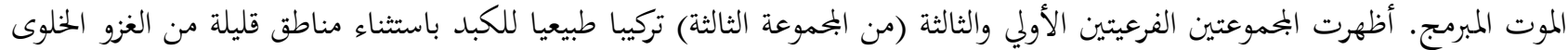

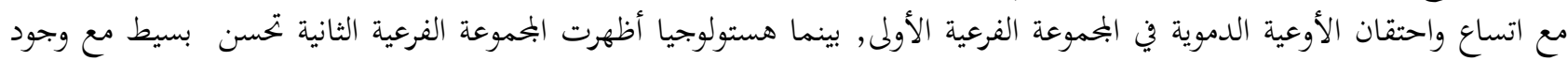

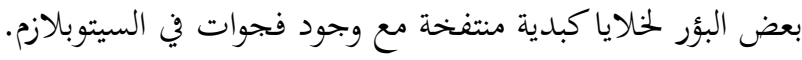

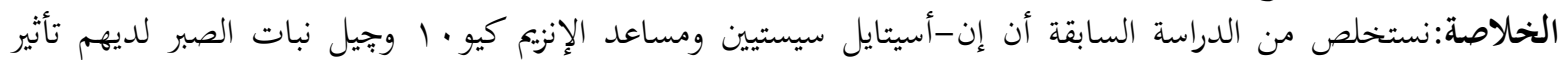

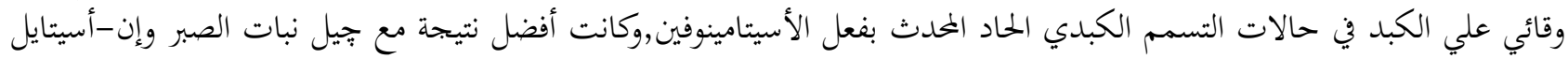

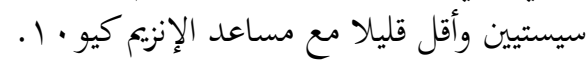

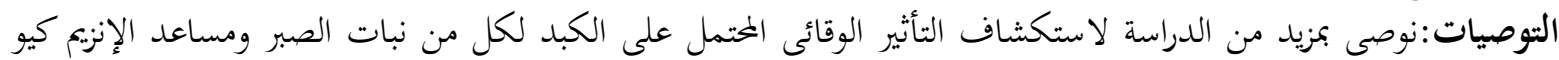

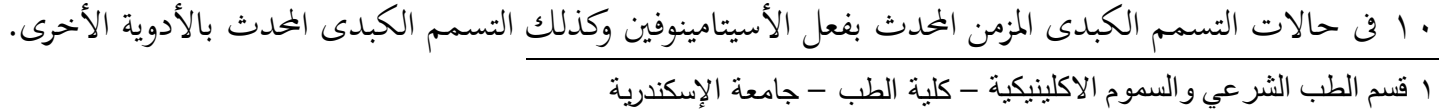
r ب قسم الكيمياء الحيوية الطيبة - كلية الطب - جامعة الإسكندرية r r قسم قسم الهستولوجي وبيولوجيا الخلية - كلية الطب - جامعة الإنكندرية 